\title{
LGBTQI+ Youth and Mental Health: A Systematic Review of Qualitative Research
}

\author{
Clare Wilson $^{1} \cdot$ Laura A. Cariola $^{1}$
}

Received: 26 September 2018 / Accepted: 7 May 2019 / Published online: 21 May 2019

(c) The Author(s) 2019

\begin{abstract}
Due to increased levels of stigma, discrimination and victimization Lesbian, Gay, Bisexual, Transgender, Queer, Questioning or Intersex (LGBTQI+) youth face particular challenges in society. With the intention of better understanding the challenges and issues that LGBTQI+ youth are experiencing, this systematic review explored qualitative studies with a focus on mental health services and the requisite social support service policies and programs for LGBTQI+ youth. Qualitative research systematically examines the expressed thoughts and feelings of the research participants, and through reflective analysis of the themes and links discussed, can provide rich and nuanced understanding. A synthesis of the included studies identified five core themes: (1) Isolation, rejection, phobia, need for support; (2) Marginalization; (3) Depression, self-harm and suicidality; (4) Policy and environment; and (5) Connectedness. Key results suggest that community, school, and family resources to support resilience will optimize LGBTQI+ mental health. This systematic review of qualitative research provides a source of rich information to inform the provision of services and policies that will address the disparity into mental health statistics for the LGBTQI+ population.
\end{abstract}

Keywords LGBTQI+ $\cdot$ Youth $\cdot$ Mental health $\cdot$ Systematic review $\cdot$ Qualitative research

\section{Introduction}

Young people experience many challenges in adolescence. Anxiety, depression and suicide are reported as causes of youth morbidity and mortality across the world (Adelson et al. 2016). Empirical studies suggest that youth who identify as Lesbian, Gay, Bisexual, Transgender, Queer, Questioning or Intersex (LGBTQI+) can find themselves faced with greater challenges, compared to youth of heterosexual orientation, as they navigate the heteronormative educational and societal institutions where children and youth spend much of their early lives (Almeida et al. 2009; Fergusson et al. 1999; Hafeez et al. 2017; Russell and Fish 2016). Online and community services, such as Rainbow YOUTH (RainbowYOUTH 2018) and InsideOUT (InsideOUT 2018)

Clare Wilson

clarecswilson@gmail.com

Laura A. Cariola

laura.cariola@ed.ac.uk

1 Clinical Psychology, Old Medical School, University of Edinburgh, Teviot Place, Doorway 6, Edinburgh EH8 9AG, UK in New Zealand and their international equivalents, are available to youth, but the provision of a positive school climate where LGBTQI+ youth can feel physically, emotionally and socially safe is vital for them to thrive during their adolescence and early adulthood. Research into mental health disparities and challenges for LGBTQI+ youth to date has a predominantly quantitative focus, and several systematic reviews provide an overview of quantitative data available on issues faced by Sexual and Gender Minority Youth (SGMY) (e.g. Brown et al. 2016; McDonald 2018). Surprisingly, there are fewer qualitative studies that contribute to an in-depth understanding of the challenges and issues that LGBTQI+ youth are facing by exploring the views and opinions of those affected. This systematic review aims to identify and obtain a comprehensive overview of qualitative studies by appraising, critically reviewing and synthesizing qualitatively derived evidence-based results and main emergent themes sourced from current literature. Special attention is given to the provision of mental health services and the requisite social support service policies and programs for LGBTQI+ youth. 


\section{LGBTQI+ Mental Health}

LGBTQI+ youth are one of the most vulnerable groups in society due to their increased risk of mental health problems. Statistics for the LGBTQI+ population estimate that New Zealand has $8 \%$ non-heterosexual youth (Clark et al. 2013), the U.S. has 7-8\% LGB youth (lesbian, gay or bisexual) (Wilson et al. 2014), and the U.K. has $4.1 \%$ of LGB young people aged 16-24 (Office for National Statistics 2016). Although LGBTQI+ represents only a small proportion of the total youth population, they are at increased risk, compared to heterosexual youth, of experiencing hostile environments at home and in wider society, and are subject to direct and indirect discrimination, harassment, disadvantage and inequality with detrimental consequences for mental health (Hudson-Sharp and Metcalf 2016).

In fact, the 2012 survey completed as part of the Youth 2000 Survey Series, Young People Attracted to the Same Sex or Both Sexes Report (Lucassen et al. 2014), stated that sexual and gender minority youth were more than three times as likely to express symptoms of depression and more than twice as likely to have self-harmed than their heterosexual peers. One in five had attempted suicide, with almost half of the respondents having thought about a suicide attempt. $41 \%$ of sexual and gender minority youth had been to see a professional for emotional support in the last 12 months, compared to $16.6 \%$ of their non-LGBTQI+ peers. The Youth 2000 Survey (Lucassen et al. 2014) also identifies a greater risk of alcohol or drug use in LGBTQI+ youth. During the same period, in Scotland, 40\% of LGBT youth considered themselves to have a mental health condition in comparison to $25 \%$ of non-sexual and gender minority youth, and bullying was identified as a key factor in distress among respondents (Mental Health Foundation 2016).

In particular, evidence suggests that sexual and gender minority youth have different risk factors and markers (Silenzio et al. 2007) and that these unique risks combined with general life stressors have the phenomenological outcome of higher levels of self-harm, suicidality and impulsivity (Liu and Mustanski 2012). These risk factors extend over the lifespan, with four times greater risk of suicide for SGM men, and both men and women being 1.5 times more likely to suffer from anxiety, depression and substance misuse (King et al. 2008). Evidence from Mental health of the non-heterosexual population of England, a 2011 study (Chakraborty et al. 2011) concludes that gay men and lesbian women have higher levels of psychological distress than heterosexuals and that discrimination may be a significant factor affecting mental health for the LGBTQI+ population.

Minority stress theory (Meyer 2003) suggests that the increased prevalence of mental health issues experienced by LGBTQI+ youth is due to the increased level of social stress, including stigma, discrimination, prejudice and victimization. Adolescence is a critical neurological development stage, with heightened effects of stress on mental health, important memory system development and a time of increased sensitivity to drug use (Fuhrmann et al. 2015). At this crucial time, feeling discriminated against by educational, medical or religious institutions, or internalizing feelings of victimization due to homophobia, transphobia or biphobia can result in significant psychological challenges for sexual and gender minority youth (Russell and Fish 2016). Evidence has consistently identified that issues such as marginalization, isolation, exclusion and bullying create social stress for sexual and gender minority youth (Grossman et al. 2009; Hafeez et al. 2017). Additionally, lack of access to understanding adults, safe places and change room facilities creates a psychological burden. However, as Bryan and Maycock (2017) point out, this can create a pathologizing phenomenon, which paradoxically may stigmatize well-adjusted and happy LGBTQI+ youth who are managing their lives in psychological comfort.

Particularly, stigma and shame create personal barriers for at-risk youth, preventing those affected from accessing services (Brown et al. 2016). McDermott (2015) suggests that embarrassment, shame and fear of stigmatization are reasons for sexual and gender minority youth to avoid seeking support from mental health services. Young LGBTQI+ people who are homeless, rural, or who are substance-users face additional barriers to seeking help (Brown et al. 2016). If support from adults or professionals is inaccessible, an alternative is for LGBTQI+ youth to find peer support and information on internet-based forums (McDermott et al. 2015; McDermott et al. 2008).

Family acceptance also has been identified as a salient influence on the mental health of sexual and gender minority youth (Sitkin and Murota 2017). Parental attachment, as described by Mohr and Fassinger (2003), is characterized by sensitivity and responsiveness to a young person's needs. If sexual and gender minority youth feel accepted and valued as individuals, there is an increased likelihood to disclose non-heteronormative status to family, and "come out," or "be out," the colloquial terms for being able to openly express LGBTQI+ orientation (Ryan et al. 2010). However, there is a disproportionate number of homeless LGBTQI+ youth, signifying that familial rejection is a significant factor for compromised mental health (Russell and Fish 2016). Durso and Gates $(2012$, p. 4) published results of a national USA online survey and found that "nearly seven in ten $(68 \%)$ of their LGBT homeless clients have experienced family rejection and more than half of clients (54\%) had experienced abuse in their family."

Adolescence is a developmental time frame within which youth explore their sexuality and for LGBTQI+ youth it will often be the time when they develop understanding of their 
own sexual and gender orientation. Within the realm of early family relational psychology, Bowlby (1962/1982) discusses changing attachments during the time of adolescence, with a subsequent shift in attachment to peers and social groups other than the family, and to institutions such as school, universities, religious or political groups. Acceptance by these alternative attachment groups is a strong protective factor for sexual and gender minority youth (Higa et al. 2014). The wider ecology of LGBTQI+ youth has a significant effect on their mental health and well-being and feelings of social connectedness to adults gives sexual and gender minority youth resilience in the face of adversity, particularly at the vulnerable developmental stage when they are establishing their sense of personal identity (Difulvio 2011).

\section{Key Themes in Quantitative Research}

The vast majority of quantitative literature on LGBTQI+ focuses on the impact of isolation, marginalization and discrimination against sexual and gender minority youth in relation to mental health outcomes, and the identification of risk and protective factors. For example, there is a robust pattern of results that demonstrated sexual and gender minority youth experience significantly higher levels of suicidality, depression, and substance misuse than heterosexual youth, which highlights the severity and prevalence of differences between sexual and gender minority youth and heterosexual youth (King et al. 2008; Lucassen et al. 2017). These results also identified higher rates of violence and victimization associated with higher levels of hopelessness and attempted suicide in sexual and gender minority youth, and also a greater potential for psychosocial problems (e.g. drug and alcohol use or abuse, risky sexual behaviors, eating disorders, and mood disorders) than reported by their heterosexual or cisgender peers. The relationship between peer victimization and sexual orientation, gender identity or expression associated with poor mental health outcomes (e.g. depression, traumatic stress, and suicidality, as well as alcohol and substance abuse) and educational outcomes (e.g. diminished school belonging, disruptions in educational trajectories) has been also confirmed in another systematic review (Collier et al. 2013). In particular, bisexual individuals have been shown to experience more psychological distress, compared to homosexual and heterosexual peers due to experiences of victimization, peer judgments and family rejection (King et al. 2008; Pompili et al. 2014).

Quantitative research has also focused on identifying risk and protective factors for mental health in LGBTQI+ youth, which has resulted in setting directions for prevention, intervention and treatment, as well as influencing laws and policies, and making advances in fostering improved mental health (Russell and Fish 2016). For example, the role of family acceptance as a protective factor in LGBTQI+ youth and young adults has been shown to be a predictor for positive mental health outcomes (e.g. greater self-esteem, social support, general health) and a protector against depression, substance abuse and suicidality (Bouris et al. 2010; Ryan et al. 2010). As such, family programs that motivate and empower parents, caregivers and other family members, have been recognized as a promising framework for community interventions that emphasize a strengths-based approach concentrating on the effects of positive parent-child relationships, rather than focusing on negative parent-child relationships and influences where a child's sexual orientation and gender identity may be seen as a "deficit." Further supporting these findings are those of a recent systematic review of literature (McDonald 2018), who identified that higher levels of social support were associated with positive selfesteem whereas lack of social support was associated with higher levels of depression, anxiety, shame and self-esteem, alcohol and drug misuse, as well as risky sexual behavior. In particular family or significant adults providing support for young LGBTQI+ is a protective factor. Family and caregiver acceptance and a sense of belonging to a peer group were identified as moderators of resilience, and thus, suggests McDonald, can be utilized in communities to support mental health outcomes.

In relation to accessing and engaging with mental health care, Brown and colleagues' systematic review (2016) identified barriers and facilitators among youth from different minority groups, including but not exclusively LGBTQI+, who had distinct needs that must be recognized by mental health services in order to improve their experiences with mental health care. In particular, findings demonstrated that barriers to access are more often identified (e.g. lack of awareness of services, stigma and shame around seeking help, issues around confidentiality, trust and anonymity), however, facilitators to support engagement with providers (e.g. community and educational programs to increase awareness of services and attitudes toward mental health services) have remained widely underexplored, and thus require further attention in future research. With regards to educational programs aimed at increasing LGBTQI+ wellbeing, safe school interventions and supportive environments such as "gay-straight alliances," sometimes referred to as the "gender and sexuality alliances," (GSAs) have been shown to have a positive effect in reduction of stigma in schools, with significantly better psychological outcomes (e.g. improvement in academic performance, feeling more comfortable in their sexual identity and empowerment), social outcomes (e.g. positive sexual diversity climates, greater sense of connectedness to their school), and also physical outcomes (e.g. lower levels of youths' self-reports of homophobic victimization, fear of safety, and hearing homophobic remarks) (Black et al. 2012; Marx and Kettrey 2016). This study also showed that the empowering of youth to be activists and 
to form their own peer supports may mediate the negative effects of marginalization and the poor mental health outcomes, including depression and suicidality.

\section{The Current Study}

The existing quantitative studies provide a rich picture of trends based on statistical indications of sexual and gender minority youth who experience adverse outcomes in a heteronormative society. In contrast to quantitative studies, qualitative approaches to the analysis of data represent an important perspective for advancing the literature by obtaining an in-depth awareness of LGBTQI+ youth and their experiences of engaging in mental health and social support services and programs. As such, qualitative research provides insight into the thoughts and feelings of the research participants, and through reflective analysis by the researcher of the themes and links discussed, can provide meaning and understanding (Sutton and Austin 2015). One of the reasons participants may voluntarily engage in this type of research is the implicit chance that the evidence will inform change by giving them a voice, hence both personal and political empowerment (Clark 2010). The key aim is to provide a comprehensive understanding of nuances of human experience through analysis and interpretation of texts and images (McLeod 2010).

Qualitative research has also been traditionally excluded from systematic reviews but it has been recognized that qualitative research provides valuable insight to inform policies and practice (Thomas and Harden 2008). In particular, with the current focus on public and individual opportunity to be involved in the development and provision of LGBT services (Gillespie et al. 2002; Ministry of Youth Development 2015; Stonewall Scotland 2018), there is international recognition of the importance of client-centered, consultative and inclusive policy development informed by the voices of services users and consumers of services. The inclusion of service user voices draws on the notion of being given the power in respect to "having a voice," and conversely, the notion of "silence" sometimes associated with feminism but equally ascribable to any marginalized or minority population (Hadfield and Haw 2001). Notably, experiences of youth are also often marginalized or they are spoken for by the parents or carers, and youth, if they do speak out, often assume that their voices will not be heard or respected as valid contributions in decision-making processes. There should be specific efforts to include youth in meaningful ways to voice their opinion in relation to matters that are of concern to them, without resulting in further inequalities. A Canadian paper, Promoting LGBT health and wellbeing through inclusive policy development, which also draws on literature from Australia, the UK and the USA, asserts that the marginalized LGBTQI+ community must be "explicitly included in policy development for a more inclusive form of health promotion" (Mulé et al. 2009, p. 2). Because youth have authentic, legitimate experiences of the problems they encounter, qualitative research involving them will improve policies and future research (McLaughlin 2015). Hence, having the voice of young LGBTQI+ people available through qualitative research is imperative if we are to address the ecological, social, and pedagogical issues and ultimately the human rights of this marginalized group (Mockler and Groundwater-Smith 2015; UNICEF 1990).

The focus of this systematic review is to provide a comprehensive overview by collating and critically appraising the existing evidence-base of qualitative research studies of the last ten years (2008-2018), a decade that has seen a global increase in acceptance towards LGBT (Flores and Park 2018), which sought to provide a youth voice in regards to mental health challenges and experiences for LGBTQI+ people. This 10 -year period has seen international changes in same-sex marriage laws, gay parenting rights, and gender reassignment as a protected characteristic (Stonewall Scotland 2018). In particular, this review aimed to identify and map themes from across the different types of qualitative research being undertaken, as well as identifying gaps in knowledge, to inform community-based LGBTQI+ service provision with a focus on ecological measures needed to support young LGBTQI+ people.

\section{Methods}

\section{Search Strategy and Eligibility Criteria}

For this literature search, several clinical psychology databases were identified to best represent the diverse fields of study relevant to this review, including ASSIA, CINAHL Plus, EMBASE, IBSS, MEDLINE and PsycINFO. With focus on qualitative studies published in the last decade characterized with marked changes of LGBTQI+ legislation, all database searches were limited to articles written in the English language, and published between January 2008 and April 2018. The search focused on international research articles appearing in peer-reviewed journals. Following the initial database search, a Google search and a manual back literature search were conducted in June 2018. The search strategy aimed to identify qualitative research literature on LGBTQI+ youth with particular attention to mental health issues, using Boolean operators and variations of the following keywords: qualitative, LGBT*, youth, young people, adolescent, teenager and mental health.

To identify relevant articles for this systematic review, inclusion and exclusion criteria were applied. Identified 
journal articles had to fulfill further inclusion criteria: (1) published between 2008 and 2018, (2) published in English language peer-reviewed journals, (3) focus on mental health of LGBTQI+ , (4) participants aged 12 to 24 years (using the New Zealand Government definition of youth age range being 12 to 24 years inclusively (Ministry of Youth Affairs 2002), (5) use of a qualitative methodology to the analysis of data. Journal articles were excluded if: (1) the study focus was on a specific, non-generalizable intervention or socio-economic population demographic, (2) the study had a medical perspective or focus on sexual health or practices, (3) the methodology did not include a qualitative methodology. All studies were evaluated according to these inclusion and exclusion criteria, and only studies that met the criteria were included in this systematic review. Studies that did not meet these inclusion criteria were discarded.

To identify relevant studies for this review, the inclusion and exclusion criteria were applied using a three-stage selection process (Meade and Richardson 1997): (a) looking only at the title, (b) looking at the abstract to identify its relevance to the research question and methodology, and (c) looking at the whole article. In cases where the researcher was not sure whether the paper was relevant and met inclusion criteria, the item was retained for the next screening stage.

Based on the outlined literature search strategy, 873 studies were initially identified. At this stage an additional manual search of Google using the same search terms and a manual back literature search of the articles included to date identified a further 21 articles. After duplicate removal and a title review of these studies, 676 were excluded and 52 were determined to meet inclusion criteria. Following another exclusion process, a total of 34 research articles were selected as having satisfied the eligibility criteria. A detailed overview of the search stages can be seen in the PRISMA Flow Diagram (see Fig. 1). The 34 articles include seven mixed methods studies where the results of the qualitative thematic analysis was deemed to add valuable data.

\section{Data Extraction}

Data of the included studies were extracted using a standardized format for systematic reviews of qualitative studies (NICE 2012a). Characteristics identified from each of the 34 studies included research questions, methods, sample size and quality assessment. The extracted data were aggregated clearly and structured in a data extraction table (see Tables 1 , 2, 3, 4 and 5). To synthesize the findings of the studies, findings were extracted from the studies and grouped into thematic categories. Subsequently, patterns were sought across the findings to provide a more comprehensive understanding of the issues of concern to LGBTQI+ population using mental health services addressed in the studies.

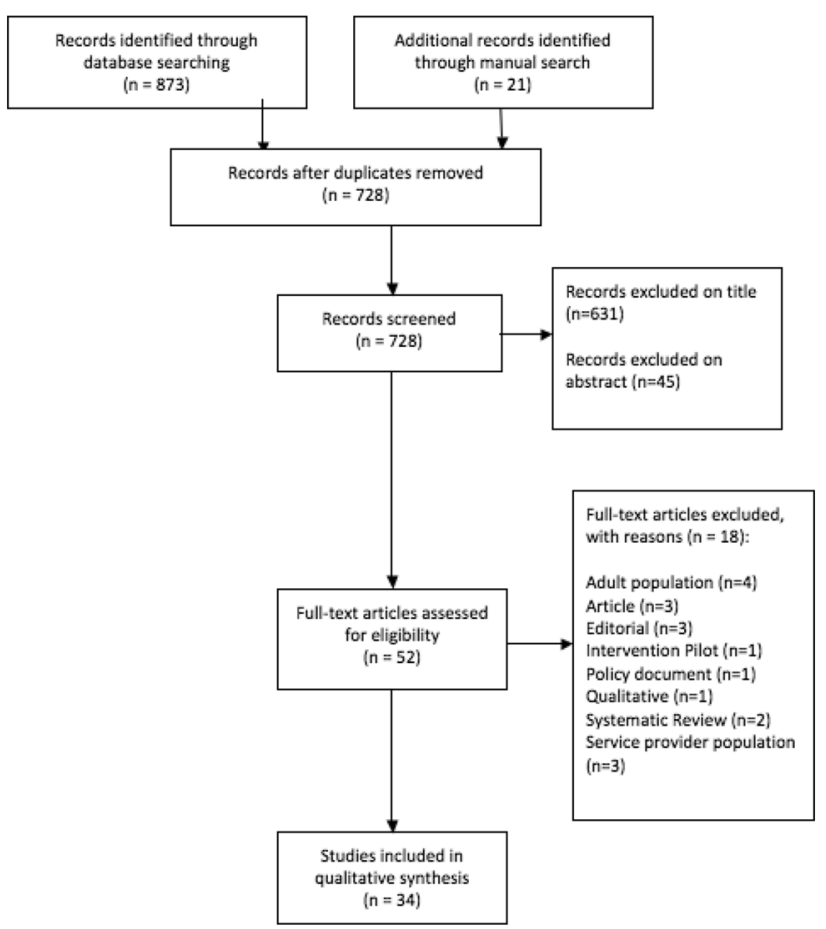

Fig. 1 PRISMA flow chart

\section{Quality Assessment}

Quality assessment of the retrieved journal articles was performed using the NICE guidelines quality appraisal checklist for qualitative studies (NICE 2012b). Following these guidelines, assessment identifies the research question and the robustness of the methodology in relation to key findings and a valid conclusion. Six main domains are assessed: theoretical approach, study design, data collection, trustworthiness, analysis and ethics. A seventh overall assessment looks at the relevance of the study and grants an overall rating; "++" where all or most of the checklist criteria have been fulfilled, and where they have not, conclusions are highly unlikely to alter; "+" where some of the checklist criteria have been fulfilled, and conclusions are unlikely to alter; or a rating of "-" where few or no criteria are fulfilled. The seven mixed methods studies included in this systematic review had quality assessment performed only on the qualitative data methodology results of the research. In relation to the qualitative assessment of this systematic review, one reviewer initially assessed the quality of the included studies and subsequently, the quality assessment was verified by another reviewer. 


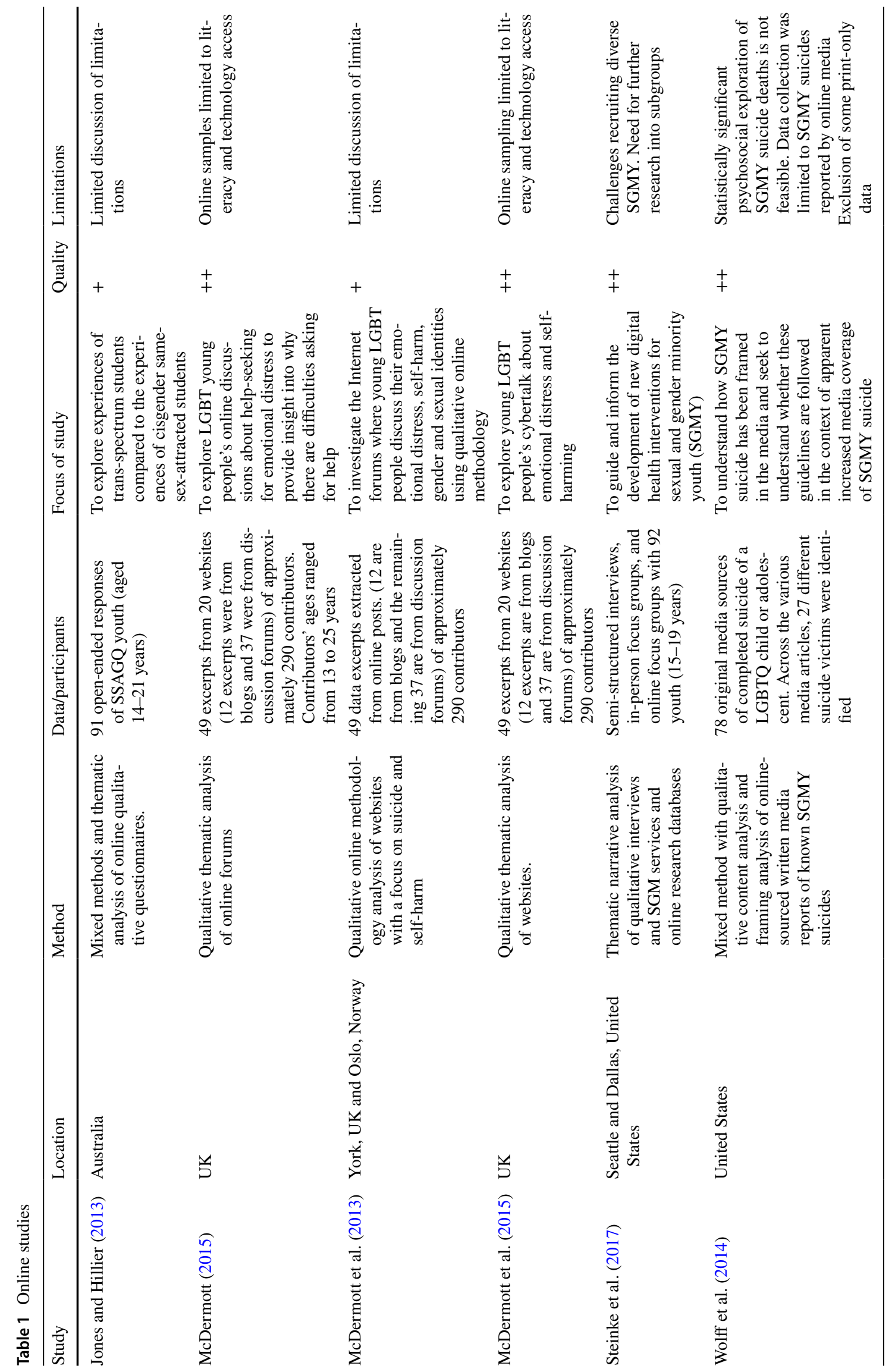




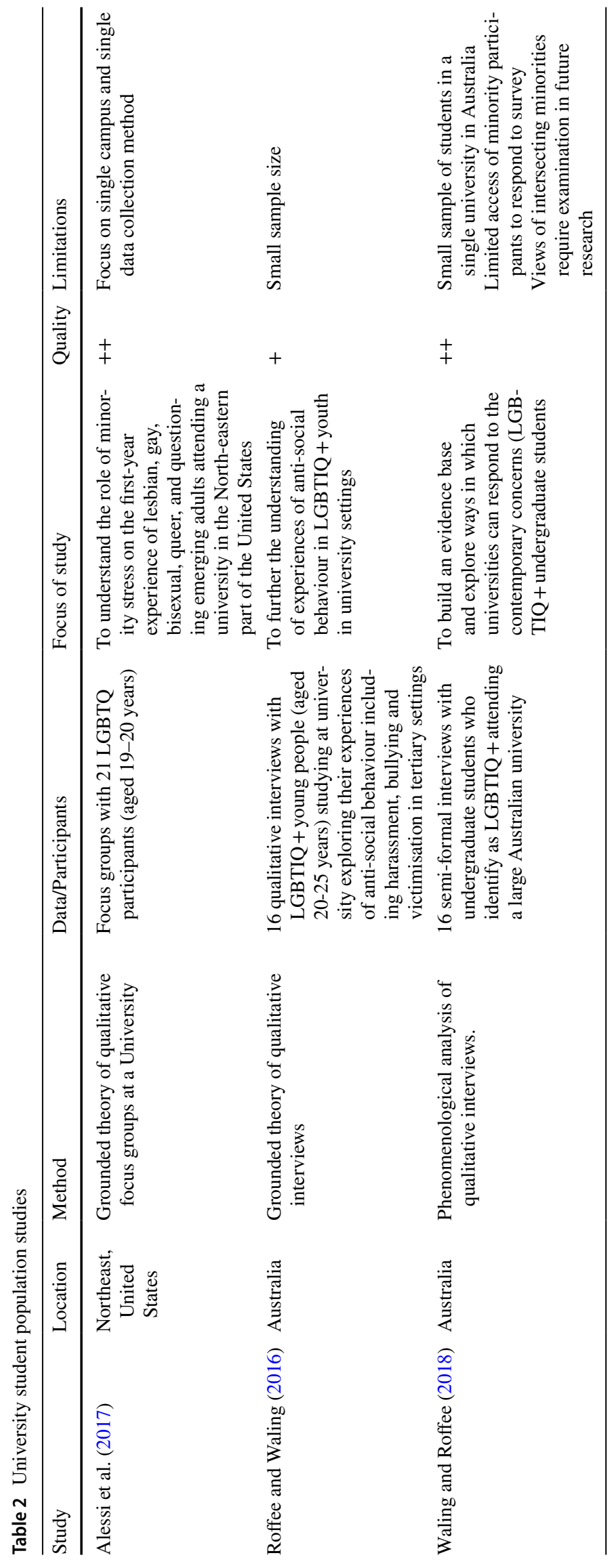




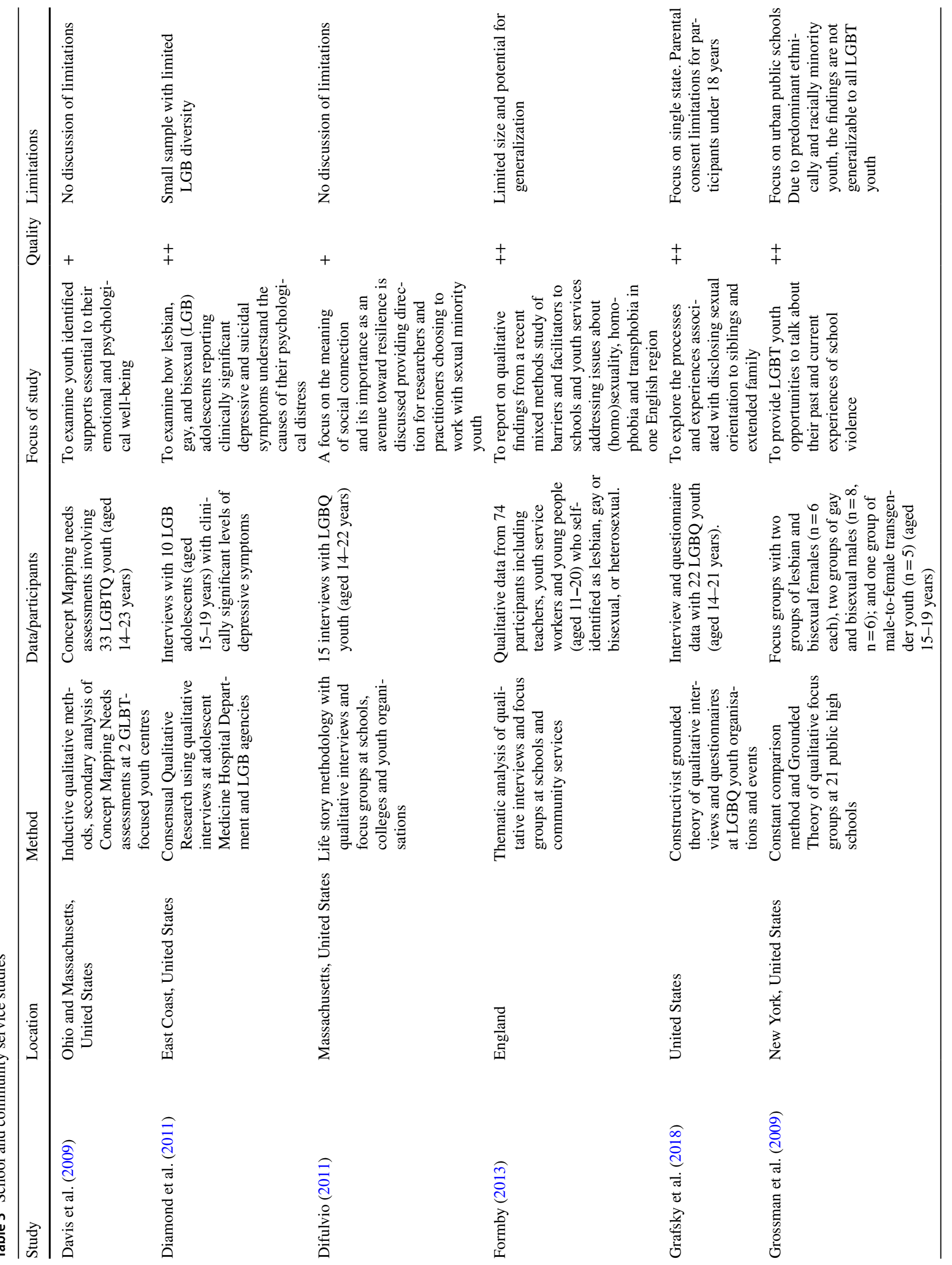




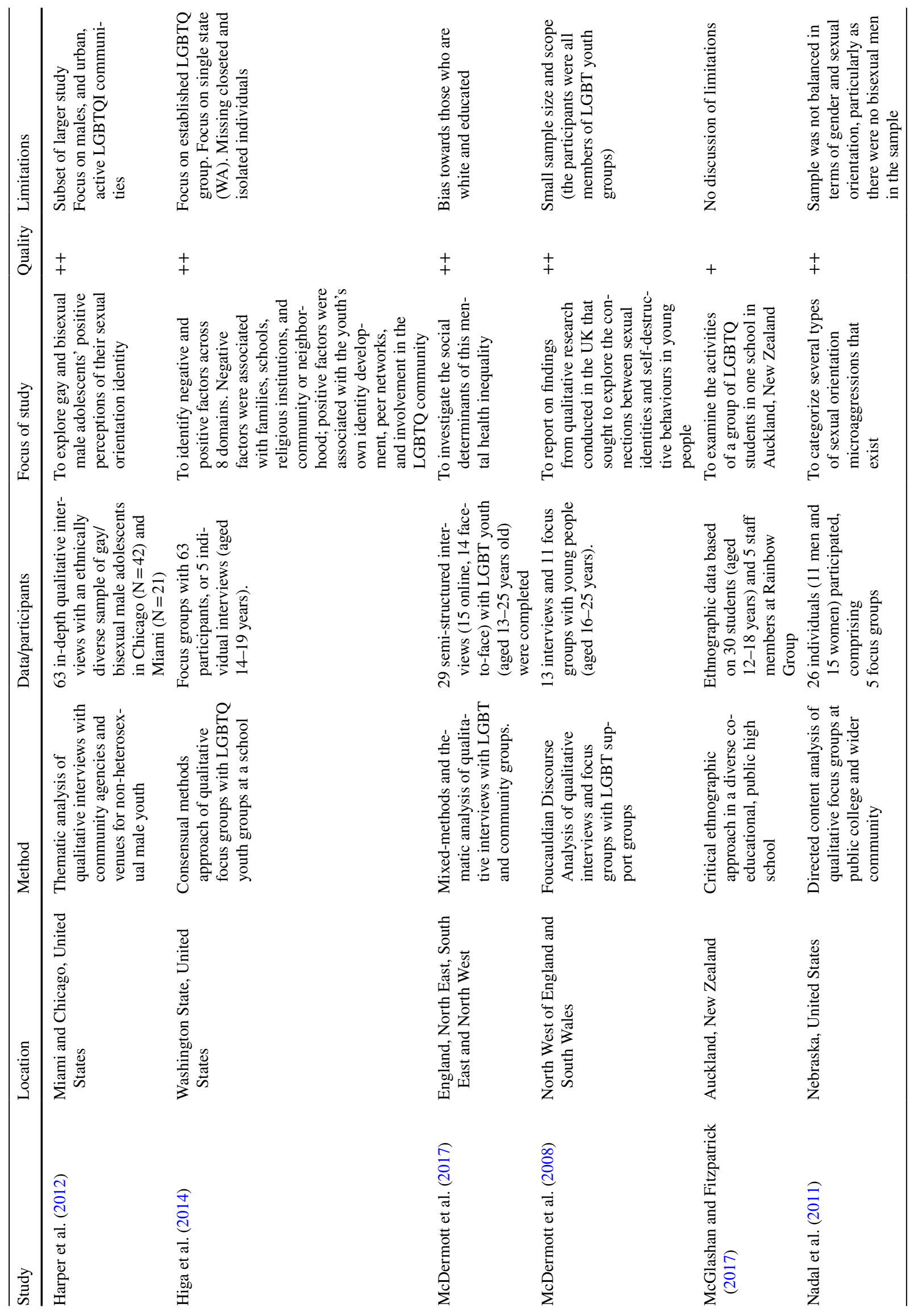




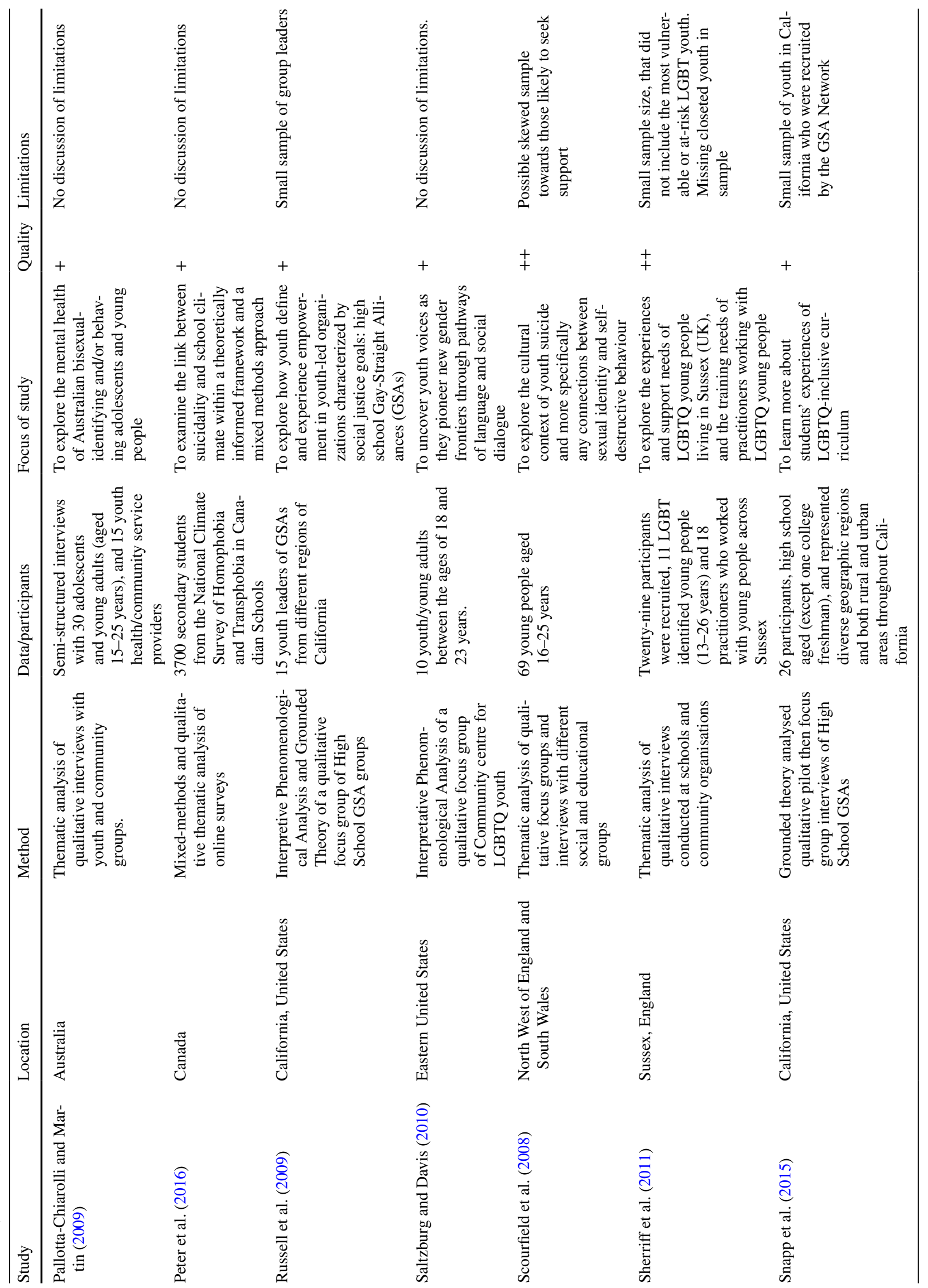




\section{Results}

The search identified 97 abstracts which were screened for relevance to qualitative research into mental health of LGBTQI+ youth. The full texts of 52 articles were assessed and 34 were identified as providing data pertaining to the aim of this systematic review. The 34 reviews were organized into five groups based on the research settings: (1) Internet search studies (see Table 1), (2) University student studies (see Table 2), (3) School or community group studies (see Table 3), (4) Studies focusing on Transgender (see Table 4), (5) Intervention studies (see Table 5). The results were compiled tables, and sorted into groups.

\section{Included Study Characteristics}

\section{Population Samples}

Of the 34 studies included in the systematic review, 19 studies $(55.88 \%)$ focused on school or community populations, 9 studies (26.47\%) were online- or Internet-based of which 3 studies were conducted using Internet-sourced data and 3 studies (8.8\%) used university student populations, 3 studies $(8.8 \mathrm{~s} \%)$ focused on transgender subjects, and further 3 studies $(8.88 \%)$ were related to the assessment of an intervention. The population numbers showed great variability from the smallest sample numbers $(\mathrm{n}=10)$ (Diamond et al. 2011; Saltzburg and Davis 2010) to the largest study population $(n=>3700)$, taken from an online study (Peter et al. 2016).

Geographical Information Of the studies included in this systematic review, 16 were done in the USA (47.06\%), with 7 studies from the UK being the next highest geographical location (20.59\%), followed by four in Australia (11.76\%) and three in New Zealand (8.82\%), and one in Canada (2.94\%). Also included were international collaboration studies between the USA and Canada (Porta et al. 2017), Ireland, the USA and Canada (Catalpa and McGuire 2018) and the Universities of York, Leicester and Oslo (McDermott et al. 2013).

Quality Assessment Of the identified studies for this systematic review, 23 studies were of high quality (67.65\%) and 11 studies were of medium quality $(32.35 \%)$. Of the 19 school and community population studies, 11 studies (57.89\%) being of high quality and $8(42.11 \%)$ of medium quality. The online Internet studies were assessed as having four $(66.6 \%)$ high quality studies, and the university student population articles had two high quality studies (66.6\%). The transgender and intervention study research groups both had all (100\%) high quality studies.
Qualitative Methods The most common methodology overall was thematic analysis, with 13 studies (38.23\%), followed in frequency by four grounded theory (11.11\%). Ethnographic and phenomenological approaches were used by three studies each ( $8.33 \%$ respectively). The remaining 11 studies (33\%) used a variety of qualitative approaches, including one Foucauldian Discourse Analysis (McDermott 2015), one Life Story approach (Difulvio 2011), and a GoAlong Interviewing technique (Porta et al. 2017). There are three identified intervention studies in this systematic review. Porta et al. (2017) used an exploratory study to get a qualitative perspective from LGBTQI+ students $(n=25)$ about bathroom facilities, Lucassen and Burford (2015) evaluated a school-based workshop offered to students $(n=229)$, and a computerized e-resource aimed at sexual and gender minority youth with depression $(n=25)$ was also evaluated (Lucassen et al. 2015).

\section{Synthesis of Themes}

An analysis of the studies' findings identified five core themes: (1) Isolation, rejection, phobia, need for support, (2) Marginalization, (3) Depression, self-harm and suicidality, (4) Policy and environment and (5) Connectedness. A diagram provides a visual outline of identified themes (see Fig. 2). The greatest proportion of studies (19) were categorized as School and Community services, and commonly identified all 5 themes, as did the Online/internet studies. The University studies concentrated on themes 1 to 4 , the transgender studies identified all but the third theme, of suicidality, self-harm and depression, whereas the predominant theme of the three intervention studies was connectedness (see Fig. 2).

Isolation, Rejection, Phobia, Need for Support Online studies, school and community based studies and transgender studies discussed themes of rejection and isolation, bullying and phobic behavior and the need for both more support and information to be made accessible to LGBTQI+ youth. Thematic narrative analysis of interviews and focus groups by Steinke et al. (2017) provided evidence of isolation as a reason that sexual and gender minority youth seek out Internet-based support channels, and further, the study by Wolff et al. (2014) of online-sourced media of completed suicides perceives isolation as both a precursor to suicidality and a warning sign of mental distress. Rejection from social, family and peer groups was a key trigger for distress in LGBTQI+ youth (Jones and Hillier 2013), and Higa et al. (2014) who identified negative and positive factors in a school-based sample, stated that the risk of rejection is potentially greater for those who are also at risk of racist or sexist bias, for example young women of color. Homophobia and transphobia towards sexual and gender minority youth 


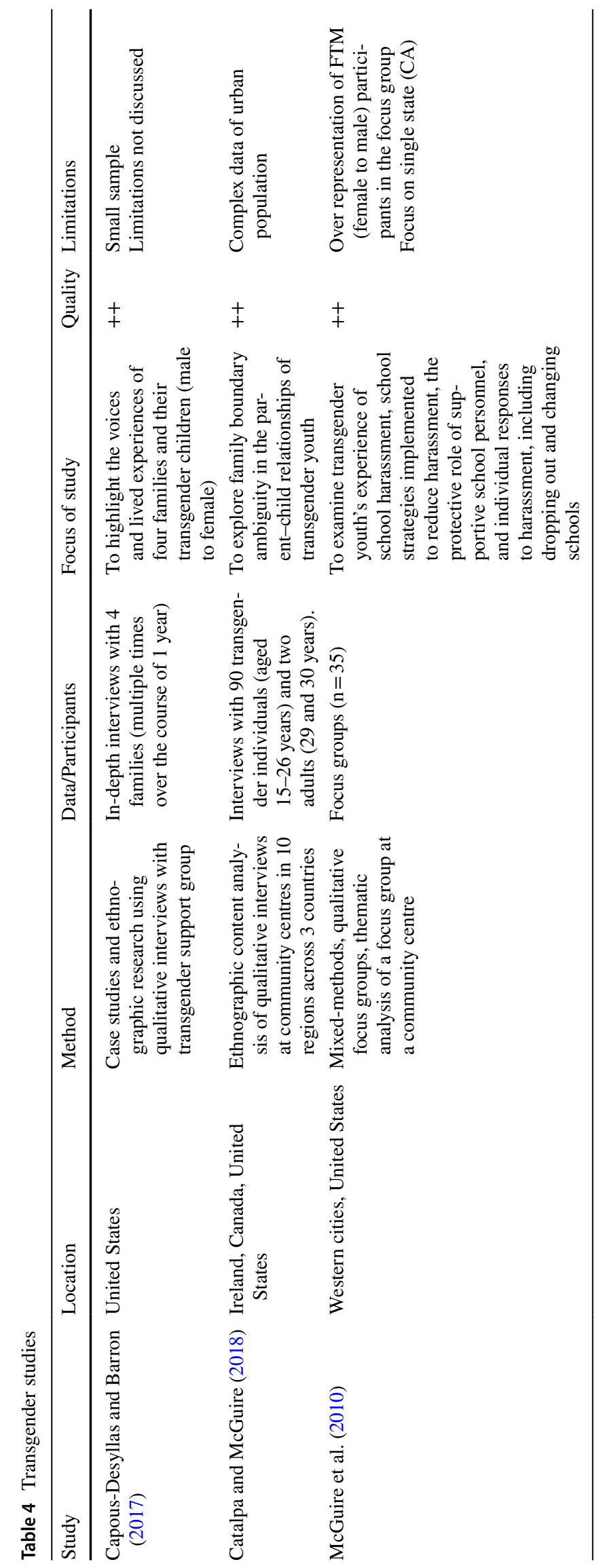




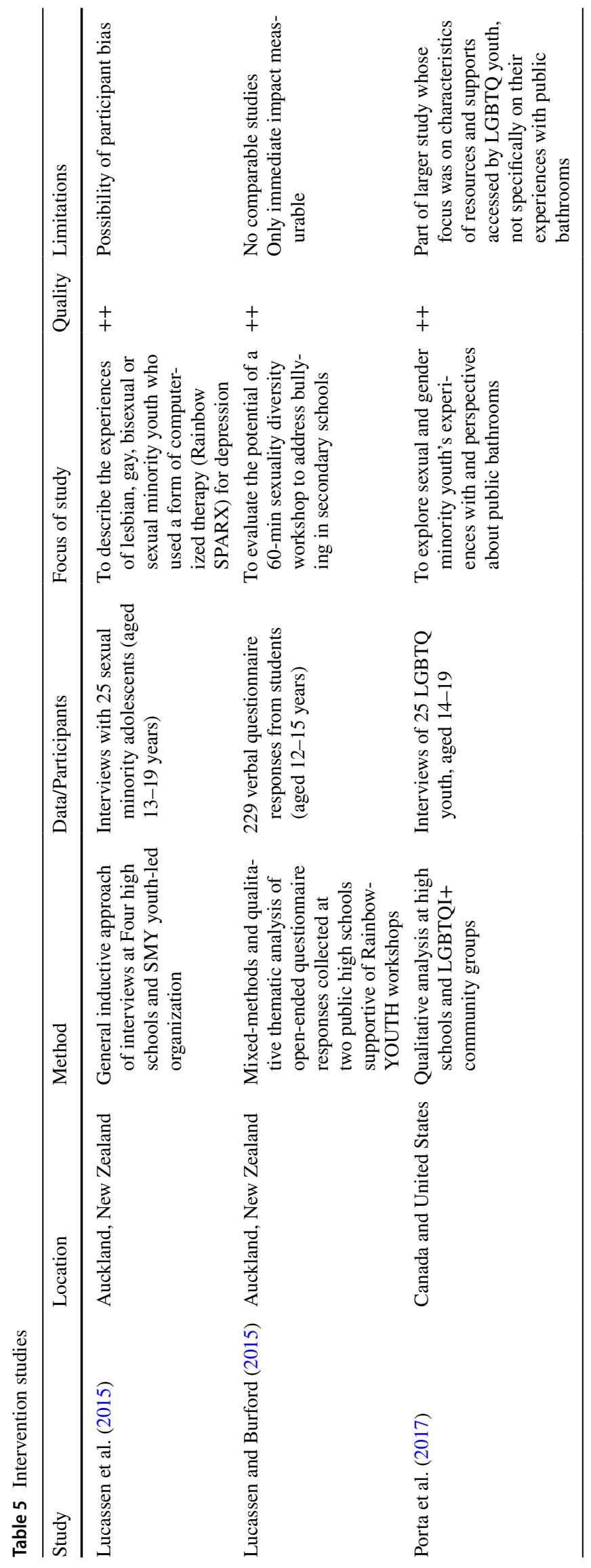


was identified across several studies (Formby 2013; McDermott et al. 2017; McDermott et al. 2008). In McDermott et al. (2017), a high quality mixed-methods study involving thematic analysis of both online and face-to-face interviews, victimization through phobic behavior and attitudes of others towards sexual and gender minority youth was described as one of the five social determinants leading to suicidality, with $70.8 \%$ of their respondents having reported experiences of homophobia, transphobia or biphobia. These concepts of discrimination are re-framed as heterosexism by Nadal et al. (2011) and Roffee and Waling (2016), where the result of such discrimination and microaggressions contributes to negative effects on self-esteem and subsequent feelings of rejection and isolation.

The need for support in school and social environments for LGBTQI+ was put forward as an important factor for mental health, and in particular the availability of peer groups such as Gay Straight Alliance (GSA) groups and safe, inclusive community gathering places and events like RainbowYOUTH meetings. GSAs were specifically described as a source of safety and advocacy for youth (Porta et al. 2017; Russell et al. 2009). In particular, Steinke et al. (2017) suggest that a lack of any such supportive community for some sexual and gender minority youth is a valid driver of the need for online LGBTQI+ community groups, which is further supported by Higa et al. (2014) by pointing out that connecting via online interventions would be especially beneficial for those sexual and gender minority youth who are geographically isolated or who are either not "out" or who are not supported by their families to attend LGBTQI+ groups. The Internet, school GSA-type groups and community groups, such as RainbowYOUTH, were all found to be sources of information pertaining to gender or sexual minority identity as well as mental health support (Steinke et al. 2017; Waling and Roffee 2018). In a secondary inductive analysis of Concept Mapping Needs Assessments at two GLBT-focused youth centers in the U.S., Davis et al. (2009) argue that as well as material resources and information, having a person to talk to was a priority for sexual and gender minority youth who access these services, stating: "In fact, needing someone to talk to was the most important idea across groups for meeting youths' emotional needs" (p. 1037).

Marginalization Closely associated to "Isolation" is the concept of "Marginalization," which can be defined as "Treatment of a person, group, or concept as insignificant or peripheral" (Oxford Dictionaries 2018). Both concepts, however can be differentiated to the extent that isolation refers to an individual experience, whereas marginalization describes the socio-political status of a population sub-group such as LGBT experiencing diminished community acceptance and systemic discrimination. The research articles identified in this systematic review put forward that marginalization for the LGBTQI+ community was a significant factor for mental health. For example, Alessi et al. (2017) conducted a grounded theory of focus groups to understand the role of minority stress and identified a continuum of marginalization experienced by first-year experience of LGBQ emerging adults attending a university in the Northeastern part of the United States. In a thematic analysis of qualitative interviews, Pallotta-Chiarolli and Martin (2009, p. 200) also talk of young bi-sexual people "feeling like marginal X-files," and the socio-political marginalization of sexual and gender minority youth makes it particularly critical that young bi-sexual people have a collective voice in order to be empowered to challenge the status quo (Russell et al. 2009). In a New Zealand ethnographic study, McGlashan and Fitzpatrick (2017) found that heteronormative environments, such as schools, create a culture where sexual and gender minority youth are more likely to be marginalized due to the dominant discourse of heterosexuality being positioned as "normal." McDermott et al. (2008) and Scourfield et al. (2008) posit that despite increasing social acceptance of same-sex partnerships, marginalization is still prevalent for sexual and gender minority youth in the $\mathrm{UK}$, and that until recently, sexual or gender orientation has not been recognized as a significant mental health risk factor, referring to the Preventing Suicide in England report (Department of Health 2012).

Depression, Self-harm and Suicidality The previously identified themes of marginalization, isolation, rejection and being victims of phobic behavior are linked to poor mental health outcomes such as depression, self-harm and suicidality (Catalpa and McGuire 2018; Diamond et al. 2011; Difulvio 2011). In particular, self-harm was identified in the transgender population as an expression of dissatisfaction with the natal anatomy and physiology which was experienced to be erroneous or undesirable (McDermott et al. 2015). Jones and Hillier (2013) state in their mixed-methodology study findings that almost half of young trans-spectrum people have self-harmed. Scourfield et al. (2008), having used interviews and focus groups in their high quality study, discuss the ways in which this self-harm can manifest, from cutting to risky behaviors, and the question of whether sexual and gender minority youth identity has direct causality to these phenomena, or whether it is one factor among many in the lives of LGBTQI+ youth which may lead to self-destructive behaviors. Bullying and victimization by homophobic, transphobic or biphobic behavior was found to be a key component in self-harm behaviors (Formby 2013; Lucassen and Burford 2015; McDermott et al. 2017; Scourfield et al. 2008; Wolff et al. 2014). The inability to disclose sexual or gender orientation, or fear of "coming out" and negative experiences following disclosure were also found 


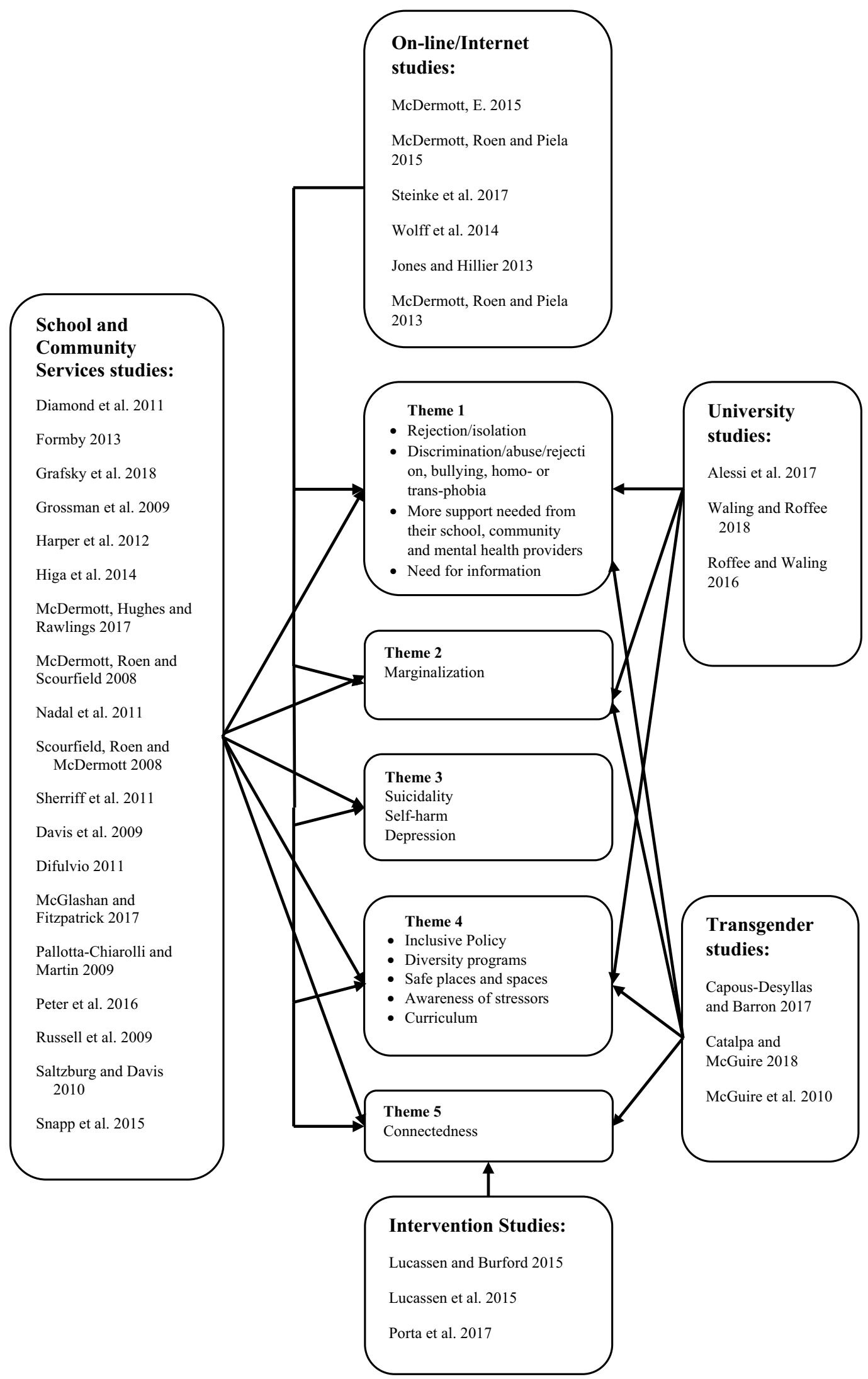

Fig. 2 Diagram of identified themes 
to be a strong predictor of depression and suicidality (Grafsky et al. 2018; Jones and Hillier 2013; McDermott et al. 2017).

Out of the 34 articles identified, 13 specifically dealt with the topic of suicide, and one online-based study by Wolff et al. (2014) was a frame analysis of completed suicides by sexual and gender minority youth in the USA, as reported in the media. The research was undertaken after a number of news reports, including six high-profile media stories involving young males aged 13 to 19 years who took their own lives in September 2010, linked the reported suicides to bullying and shame. Peter et al. (2016) also undertook research following a well-publicized youth suicide a year later in Canada, subsequent to reports of victimization, depression and self-harm for much of the victim's life, and as with Wolff et al. (2014) there was a strong link between the suicide and a hostile school and community climate.

Policy and Environment The "Preventing Suicide in England" report outlines how many LGBT pupils who are victims of bullying experience further negative academic, social and mental health outcomes, with the impact possibly persisting into adult life (Community Mental Health and 7 Day Services 2017). Hence, it is imperative that schools are safe, inclusive environments where pupils are able to learn and fulfill their potential. Developing and establishing inclusive policies that address bullying and homophobic, transphobic or biphobic behavior was a consistent theme from all groups of the identified studies. Several studies had school policy as a focus (Grossman et al. 2009; Peter et al. 2016), whereas others looked at the wider ecology of community and agency or government level policy (Harper et al. 2012; Pallotta-Chiarolli and Martin 2009; Scourfield et al. 2008). Curriculum inclusion of LGBTQI+ relevant topics was identified as an additional way to recognize diversity, particularly in the subject areas of health, humanities and the social sciences such as history (Formby 2013; Snapp et al. 2015). However, Formby's (2013) high quality study of interviews and focus groups involving teachers, youth service workers and youth found that there was a disparity between the "visibility" of gay youth among their peers and the taboo nature of homosexuality within the school curriculum.

Formalized diversity programs and safe meeting spaces at educational institutions as well as community-based social groups such as RainbowYOUTH were strongly recommended for supporting the mental health of sexual and gender minority youth. The GLSEN report (Kosciw et al. 2014, p. 68) states that: "Students who attended schools with a GSA were much more likely to report that their classmates were accepting of LGBT people." Using phenomenological analysis of interviews conducted with undergraduate students who identify as LGBTIQ + attending a large Australian university, Waling and Roffee (2018) focus on diversity and inclusion programs in higher education facilities, whereas Lucassen and Burford (2015) evaluated the potential of an intervention involving a sexuality diversity workshop that was delivered in a high school setting in New Zealand. Having facilities such as bathrooms and changing rooms, which are gender neutral, therefore inclusive, was a recommendation from research conducted in Canada and the US (Porta et al. 2017) and Australia (Waling and Roffee 2018). In New Zealand a guide produced for schools (Ministry of Education 2015), directs that schools not only challenge bullying and marginalization of students, but also delivers a mandate to engender diversity through gender-neutral uniform policies and consideration of such things as inclusive sports and extracurricular events, and allowing same-sex partners for school dances, which address the needs of sexual and gender minority youth throughout the wider school community, rather than solely through the curriculum (McGlashan and Fitzpatrick 2017).

An important consideration for educators and professionals working with youth is continuing education on LGBTQI+ issues, as Wolff (2014) asserts that appropriate support for LGBTQI+ youth from educators and mental health professionals can mitigate the stress of "coming out" and navigating a heteronormative environment. Sherriff et al. (2011) and Jones and Hillier (2013) suggest that the needs of sexual and gender minority youth are not being met by community and educational services and that training for service providers is imperative, with opportunities provided to hear the voice of young LGBTQI+ as part of such training, so that subjective experiences of sexual and gender minority youth are heard and understood by professionals. The findings of Scourfield et al. (2008) evince "the need for sexual cultural competence in practitioners." Likewise Snapp et al. (2015) advocate staff training policies on LGBTQI+ issues.

Connectedness Sexual and gender minority youth connectedness to others was identified in the context of smaller groups such as GSAs, which then become part of a wider network that grants empowerment to marginalized LGBTQI+ youth (Russell et al. 2009). As such, the sense of solidarity and friendship in the face of isolation and a physical place such as GSA or community group, where sexual and gender minority youth can be physically and mentally safe while forging connections with peers, was found to be a vital protective factor for LGBTQI+ youth (Davis et al. 2009; Russell et al. 2009; Saltzburg and Davis 2010; Steinke et al. 2017). In the absence of these physical spaces an online support forum is an acceptable alternative (McDermott et al. 2015; Steinke et al. 2017). McDermott (2015) discusses the problems facing young LGBTQI+ in a heteronormative society and the difficulties they face in finding support and 
information, resulting in peer group interaction online being a strategy used to cope with emotional distress.

Parental and family acceptance for sexual and gender minority youth and the potential for disconnect was identified as a significant mental health factor (Diamond et al. 2011; Grafsky et al. 2018; Scourfield et al. 2008; Wolff et al. 2014). Parental acceptance versus rejection was signified in the transgender studies as key to resilience for transgender youth (Catalpa and McGuire 2018; McGuire et al. 2010). Capous-Desyllas and Barron (2017) discuss the concept of loss for parents of gender-variant children and learning to love and accept their child unconditionally, as well as issues of transgender youth acceptance by other ecological groups such as medical providers and religious communities. Having one caring adult providing connection and understanding, who is both confidante and advocate, is an invaluable resource for young LGBTQI+ people in their navigation of the heteronormative institutions of their early life ecology (Porta et al. 2017).

Each of the five themes identified in this systematic review of qualitative research intersect and overlap. The key overarching findings from the qualitative studies into mental health of LGBTQI+ youth are summed up succinctly by Higa (2014) stating that there is a need to address the persistent prejudice that can be experienced by LGBTQ[I+] youth in their community institutions and ecology.

\section{Discussion}

Qualitative research into mental health issues experienced by LGBTQI+ youth, while not commonly undertaken, is essential to the provision of understanding and insight for community service providers, health professionals and for the youth themselves. Without a LGBTQI+ youth voice to influence policy and practice it is challenging to provide support within their ecosystem where the needs of these youth can be met. For this population much of their time is spent in their family, school or community environment, where acceptance and the ability to express their authentic self is paramount to mental well-being. To this end, this systematic review aimed to identify studies using qualitative research methods of enquiry into mental health in young LBGTQI+ people. Findings revealed consistent themes across the research methods and populations studied. 34 articles of high and medium quality with diverse content and focus were identified as relevant to the aim of this review. A subsequent synthesis identified five groups that characterize the focus and settings of the studies: online or internet based, school and community populations, university setting, focus on transgender, and intervention programs. These five characteristics of populations and setting further revealed five core themes relating to the mental health challenges faced by sexual and gender minority youth including (1) Isolation, rejection, phobia and need for support, (2) Marginalization, (3) Depression, self-harm and suicidality, (4) Policy and environment and (5) Connectedness.

In relation to the first core theme, isolation, rejection, phobia and need for support, this review identified that the internet is one means of addressing this isolation and need for support. Online websites, forums, chat groups and information services were identified as a valuable resource for sexual and gender minority youth, especially those who had limited access to other ecological supports (Capous-Desyllas and Barron 2017; Higa et al. 2014; Steinke et al. 2017). Paradoxically, online forums are perceived as a safe and accessible means for LGBTQI+ to access information, regardless of disclosure status, and to make meaningful connections with supportive peers (Hillier et al. 2012). For example, the GLSEN study (GLSEN CiPHR and CCRC 2013) found that two-thirds (62\%) of sexual and gender minority youth had connected with other LGBTQI+ youth via the internet in the previous year, and sexual and gender minority youth were five times more likely to have looked online for information pertaining to their sexuality $(62 \%)$ than their non-sexual and gender minority youth peers (12\%), and for information regarding health $(81 \%$ sexual and gender minority youth versus $46 \%$ non-sexual and gender minority youth).

In addition, the mental health risk factors of rejection and need for a supportive network can be addressed via access to school and community cultures and services where sexual and gender minority youth feel welcomed, accepted and valued. In relation to educational and social environments, government agencies have consistently acknowledged that having safe and supportive social environments in which to live and learn is a strong protective factor for the mental health of LGBTQI+ youth (Government Equalities Office 2018; Ministry of Youth Development 2015; U.S. Department of Health and Human Services 2017). Availability of support groups in the community and schools, such as RainbowYOUTH or GSAs provide connections for marginalized sexual and gender minority youth to interact with peers, access information and find a collective voice (Poteat et al. 2016). In particular, having such a collective voice in the face of bullying, victimization, stigmatization, homophobic, transphobic or biphobic behavior can lead to activism and civic engagement (Poteat et al. 2018; Russell et al. 2009). Social activism can act as a resilience factor for transgender youth and also ascribe the self-affirming value of being a role model for others (Singh et al. 2011).

By examining the findings of qualitative research reported in the last decade, it is clear that discrimination, marginalization and victimization cause much of the distress experienced by sexual and gender minority youth (King et al. 2008; Liu and Mustanski 2012). In relation to the second core theme, the socio-political marginalization of sexual 
and gender minority youth is responsible for feelings of systemic discrimination. This holds particular importance in predominantly heteronormative institutions such as schools, where straight cisgender individuals are "normal" and therefore sexual and gender minority youth are "not normal" (McGlashan and Fitzpatrick 2017). While acknowledging the marginalized status of LGBTQI+ youth, attention must be also paid to avoid pathologizing sexual and gender minority youth, either in their gender expression or sexual orientation, or in respect to having mental health issues (Drescher 2015; Lerner and Robles 2017; McDermott et al. 2015). Harper et al. (2012) describe adolescence as a time of developing one's unique identity and acknowledge that research to date into mental health challenges for sexual and gender minority youth is crucial. At the same time, however, Harper et al. (2012) posit that many young LGBTQI+ are resilient and well-adjusted and that future research might benefit from a strengths-based focus.

Of particular relevance to the third core theme "depression, self-harm and suicidality," resilience-focused research may grant insight into these poor mental health outcomes for sexual and gender minority youth. If almost half of trans-spectrum youth have self-harmed (Jones and Hillier 2013) and the link between suicide and mental distress due to sexual and gender minority youth status is established (Peter et al. 2016, Wolff et al. 2014), then it is imperative to find ways of addressing these statistics and finding interventions that support and moderate the levels of depression and self-destructive coping mechanisms. This systematic review also identified a recommendation for service providers such as teachers, community workers and medical staff to have access to education on issues including suicide prevention, bullying interventions and sensitivity training (PallottaChiarolli and Martin 2009; Scourfield et al. 2008; Sherriff et al. 2011)). It was not until 1987 that homosexuality was removed from the Diagnostic and Statistical Manual (DSMIII-R) (American Psychiatric Association 1987) and in 1990 removed from the International Classification of Diseases (ICD-10) (World Health Organisation 1990) as a diagnostic category of psychopathology. Despite gains in civil rights, there is persistent discrimination against LGBTQI+ people (Dessel and Rodenborg 2017; Drescher 2015). Although attitudes are changing, societal misperceptions and discomfort about homosexual behavior and identity are persistent even among health care personnel (Dessel and Rodenborg 2017; Mayer et al. 2008; Scourfield et al. 2008). Changing attitudes and developing cultural competence is an ongoing socio-political process. To this end, Youth Scotland (LGBT Youth Scotland 2018) sets gold standards for achievement at LGBTQI+ inclusivity in the LGBT Charter program to which educational institutions can strive. This was achieved through consultation with LGBT service providers and their users and has provided a framework for organizations to develop their own LGBT policies and practices. Hence, this type of LGBTQI+ Charter community initiative, and the provision of ongoing training for professionals who work with youth, will increase efficacy and cultural competence for service providers and support emotional safety for sexual and gender minority youth (Kull et al. 2017; Swanson and Gettinger 2016).

In relation to policy and environment, the fourth key theme identified in this review, many western countries are fostering inclusive and non-discriminatory legislation and services, such as the Youth Scotland initiative. Most western nations have, at least in urban areas or online, support organizations such as RainbowYouth in New Zealand or MINUS18 in Australia. However, in the global context of LGBTQI+ mental health, it is notable that in more than 70 countries it is still illegal to be homosexual (United Nations 2011). The United Nations Committee on the Rights of the Child (2003) states that: "parties have the obligation to ensure that all human beings below 18 enjoy all the rights set forth in the Convention without discrimination, including with regard to 'race, color, sex, language, religion, political or other opinion, national, ethnic or social origin, property, disability, birth or other status.' These grounds also cover adolescents' sexual orientation and health status." There is still much to be done in the international arena at the very basic level of human rights before all sexual and gender minority youth are accepted and need not face discrimination.

Connectedness, the final core theme, is key at a societal level, where finding a group of peers fosters not only wellbeing but also opportunities for empowerment, solidarity and networking (Russell et al. 2009). Possibly the most important ecological environment within which connectedness engenders good mental health is that of the family, where attachment to parents or caregivers and acceptance by siblings and other family members leads to resilience in the face of more hostile community or societal institutions (Catalpa and McGuire 2018, Ryan et al. 2010). Young people who identify as sexual or gender minority are a high-risk group who are developmentally vulnerable (Liu and Mustanski 2012) and the family environment has been identified as an important protective factor against stressors and mental health problems in LGBTQI+ youth. For example, in Growing up LGBT in America, a national survey of LGBTQI+ youth in the USA (Human Rights Campaign 2012) the most important factor identified as a problem in their lives was non-acceptance by families (26\%). A lack of family connectedness or acceptance compounds the issues that sexual and gender minority youth have at school, further hindering their learning (Mallory et al. 2017), and suicidality in youth has been shown to be related to family connectedness, identified as the most protective factor against suicidal ideation and attempt (Stone et al. 2015). 
From a resilience perspective, in The Health of $L G B T Q$ Youth: Risk and Protective Factors, a Canadian report (Buote et al. 2012), family support for sexual and gender minority youth resulted in prevention of suicide, more positive levels of mental health, less substance use, better coping skills and more openness about their sexual or gender identity. Evidence supports these findings that family acceptance is protective for negative health outcomes such as depression, substance abuse, and suicidality (Ryan et al. 2010; Stone et al. 2015). This evidence underpins connectedness to and acceptance by family members of sexual and gender minority youth as a crucial factor for their mental health and well-being.

\section{Limitations and Future Directions}

Although this systematic review provides an important overview into the qualitative research that is being carried out, it has some limitations. Variations in the terminology used in LGBTQI+ literature and resources are extensive, and at least 23 variations on gender or sexual minority descriptors are in common use (Trans Student Educational Resources 2018). For this systematic review the general key term "LGBT*" was used in the search criteria, which may have excluded some articles that used terms such as non-binary, or noncisgender. As such, the results obtained in this systematic review cannot make any valid and generalized statements about mental health needs and resources of specific groups that are represented under the LGBTQI+ label. To increase the population represented under the LGBTQI+ umbrella and to increase the level of specificity of the results, future systematic reviews should comprise a wider range of key terms that would provide a broader insight and overview of mental health and well-being in LGBTQI+ youth.

Such a relatively inclusive and broad use of key terms needs to be aligned with a set of equally broad research aims and questions. In this regard, to produce more valid results in relation to the various LGBTQI+ groups, future systematic reviews should narrow their search terms to increase the level of specificity, and thus be able to provide applicable and valid recommendations to improve mental health supports to the specific LGBTQI+ groups. Whereas characteristics of the identified studies varied greatly in respect to aim, sample size, methodology, population base and focus, which further impinges on the generalizability of the results, future systematic reviews could focus more specifically on certain criteria. Thus, systematic reviews should define from the onset the scope of the review and its desired level of generalizability to inform appropriate key term selection, methodological characteristics and research aims questions.

Deriving evidence to identify the mental health needs of LGBTQI+ groups is of great societal importance, as for example, transgender adolescents are particularly vulnerable as they navigate the cisgender world and manage the challenges of a changing body in which they do not feel they belong (Perez-Brumer et al. 2017; Peterson et al. 2017). However, there are noticeable limitations in gaining access to rich, experiential, qualitative data from transgender youth, their families and peers, which restricts understanding of mental health resource priorities for transgender youth. This gap in qualitative research relates to the issues and problems faced by families when adjusting to a child who wishes to change their gender expression, the complex nature of acceptance and coping in this situation, their possible resistance and the dynamic relationship between families and their access to services (Tishelman et al. 2015). Thus, systematic reviews are only able to synthesize existing data, and it becomes apparent that qualitative studies that explore lived experiences of LGBTQI+ youth within their family context are widely under represented. Here future empirical research needs to invest greater resources to produce more high quality studies that can be then included in systematic reviews.

The majority of the studies included in this systematic review $(58.3 \%)$, identified their study population through school and community groups. These studies pointed out the difficulties in recruiting populations for research into LGBTQI+ youth and the effects this has on obtaining robust empirical evidence. In this sense, unknown numbers of youth who have not disclosed their sexual identity or who have barriers to accessing community support are not represented in any empirical research as to their mental health status or needs. The complexities of recruitment challenges and data collection are further confounded by the hidden nature of those who feel they cannot disclose due to cultural and ethnicity-based considerations of individual ecologies. Some of the research is Internet-based and thus only sexual and gender minority youth with access to the World Wide Web and computers or digital devices can be involved. Thus, the question remains largely unanswered of how many youth struggle with mental health issues because they feel different from heteronormative societal models but find no avenue to gain support, a sense of belonging or resources. This highlights wider patterns where voices of youth are marginalized in society and efforts to include youth in research, as outlined by the UN Convention on the Rights of the Child (1990), often results in further inequalities as youth of advantaged backgrounds have more opportunities for inclusion compared to disadvantaged youth. This leads then into a self-perpetuating cycle of exclusion. Here social science research needs to find ways to include youth across the social spectrum so that their voices are heard.

It is also important to mention that this study did not examine cultural, ethnic and faith-based differences in acceptance of LGBTQI+ youth. Religious beliefs and cultural homophobia, transphobia and bi-phobia are existing 
ecological factors in the lives of young sexual and gender minority youth that affect the level of societal and familial inclusion or exclusion experienced. The lack of data across cultures, genders, orientations and ethnicities is especially challenging for researchers, with some minority ethnic groups particularly underrepresented (Collier et al. 2013). Here, future research needs to be more rigorous to explore the relationship between culture, ethnicity and religion to obtain a better understanding of the wider socio-cultural influence on levels of experienced societal acceptance or exclusion of LGBTQI+ youth.

The review was also based on peer-reviewed journals that were published in empirical research over the last ten years, and hence literature selection was time limited and not exhaustive. As such future research could explore a wider range of available empirical research (e.g. book chapters and Ph.D. dissertations) and grey literature (e.g. government reports and policy statements), that extends beyond the 10-year time span of the present systematic report, to provide a more comprehensive insight into the topic. This would be of particular importance when tracing, comparing and mapping out existing debates and narratives, and their evolution over time, to derive a better understanding of mental health and wellbeing in LGBTQI+ youth.

\section{Implications for Research and Practice}

This is the first systematic review of qualitative research into the mental health of LGBTQI+ youth. Qualitative research provides a voice for the research participants to offer authentic experiential and perceptual evidence that can be used to inform and influence policy and mental health service provision from an evidence-based perspective. This systematic review provides a reference of qualitatively derived evidence-based knowledge by mapping out the themes and findings of qualitative research into LGBTQI+ mental health over the last decade.

The first implication for practice relates to the recognized and mandated provision of safe spaces and places in educational institutions and in the community with an emphasis on client-centered policy and in community planning at micro and macro levels of civil and state governance. For example, school and community level GSA-type services provide support within the micro-ecology of the young person whereas international law preventing discrimination on the grounds of sexual or gender minority status legislates at a global level. The provision of collective social opportunities facilitates a collaborative and united voice and empowerment to gain socio-political influence and thus to drive change for LGBTQI+ youth. As such a unified resistance to victimization and stigmatization challenges the pervasive heteronormative discourse, where, in particular, institutional policies must address bullying and marginalization of sexual and gender minority youth while demanding a cultural environment of inclusivity and acceptance.

A second implication for practice is the targeted education of service providers in all social, educational and health agencies and continuing efforts to address transphobia, biphobia and homophobia. To address disparities in wellbeing of sexual and gender minority youth, it is of vital importance to ensure that services for LGBTQI+ youth, such as drug and alcohol support, mental health services and sexual health clinics, adhere to a welcoming and inclusive ethos. Within these services, the provision of support must be provided by key adults with whom sexual and gender minority youth can make connections and feel valued in their identity choices.

This systematic review also identified directions for future research. For example, the Minority Stress Theory (Meyer 2003), with a focus on increased prevalence of mental health problems experienced by LGTBQI+ youth due to increased levels of social stress, (e.g., stigma, discrimination, prejudice and victimization), might provide a framework for further research to fill gaps in the knowledge to date. It is also vital that future research focuses on continued exploration of effective platforms for internet-based services, such as online forums, as a critical information resource, both for researchers to obtain an in-depth understanding of LGBTQI+ youth and their experiences relevant to mental health, and for the sexual and gender minority youth themselves. Thus these forums provide sexual and gender minority youth a means of access to help and advice online, and the experience of social networking, acceptance and connectedness. Further research is also needed within the realm of online e-therapy interventions such as Rainbow SPARX (Lucassen et al. 2015) that can be used as a treatment option for any LGBTQI+ youth that are experiencing emotional distress regardless of access to community services and disclosure status.

Transgender youth in particular are vulnerable to social isolation in the face of rejection by family and other ecological supports, and studies demonstrate the significantly greater number of homeless LGBTQI+ youth (Crossley 2015; Matthews et al. 2018; Oakley and Bletsas 2018). Thus it is of great importance that research investigates specific risk factors and markers for marginalized youth with a focus on the disparities in suicide and self-harm rates for sexual and gender minority youth. Similarly, there is a need for qualitative research to support quantitative evidence as well as interventions through social policy (Durso and Gates 2012; Kidd et al. 2017; McDonald 2018; Prock and Kennedy 2017). More strengths-based enquiries are needed into resilience and protective factors for sexual and gender minority youth and the ecological, psychosocial and cognitive characteristics of young LGBTQI+ people who are leading happy, well-adjusted lives within their microsystems 
and macrosystems. By having access to these rich qualitative data that can be evinced from analysis of nuanced lived experiences of marginalized but adaptive members of their communities, further support mechanisms can be devised and implemented with sexual and gender minority youth who are less resilient. Also, as suggested by Collier et al. (2013), there is a need for more longitudinal studies to provide data into the long-term outcomes, especially considering the developmental differences across adolescence.

\section{Conclusion}

Although quantitative investigations into sexual and gender minority youth have revealed poor mental health outcomes, and identified risk and protective factors, there are gaps in our understanding of how these effects arise. To address this we performed a systematic review of qualitative investigations into the experiences of LGBTQI+ youth. The results identified five core themes: isolation, rejection, phobia and need for support; marginalization; depression, self-harm and suicidality; policy and environment; and connectedness. These five themes became apparent across the differing methodologies and population samples, providing rich information. The implications for policy, practice and future research are clear from this synthesis of research findings. The voices of LGBTQI+ youth call for inclusive environments, acceptance and support from service providers and family members, and a community to which they can belong, either in their own geographical ecology or internet-based. Addressing these key needs provides resilience in the face of marginalization, isolation, and victimization. Safe environments and anti-discrimination policy alleviate the stressors which make the challenges faced by sexual and gender minority youth greater than those of their peers. These results provide a source of rich information to inform the provision of services and policies that will address the disparity into mental health statistics for the sexual and gender minority youth population.

Acknowledgements The authors would like to thank the researchers of the included articles for their diligence in applying qualitative research methods to exploring LGBTQI+ youth and mental health.

Authors' Contributions CW conceived of, designed and conducted the systematic review, analyzed the data and drafted the manuscript; LAC supervised the study, guiding the analysis of the data and contributing to the writing and editing of the manuscript. All authors read and approved the final manuscript.

\section{Compliance with Ethical Standards}

Conflict of interest The authors declare that they have no conflict of interest.
Open Access This article is distributed under the terms of the Creative Commons Attribution 4.0 International License (http://creativeco mmons.org/licenses/by/4.0/), which permits unrestricted use, distribution, and reproduction in any medium, provided you give appropriate credit to the original author(s) and the source, provide a link to the Creative Commons license, and indicate if changes were made.

\section{References}

\section{*Denotes study included in systematic review}

Adelson, S. L., Stroeh, O. M., \& Ng, Y. K. W. (2016). Development and mental health of lesbian, gay, bisexual, or transgender youth in pediatric practice. Pediatric Clinics of North America, 63(6), 971-983. https://doi.org/10.1016/j.pcl.2016.07.002.

* Alessi, E. J., Sapiro, B., Kahn, S., \& Craig, S. L. (2017). The firstyear university experience for sexual minority students: A grounded theory exploration. Journal of LGBT Youth, 14(1), 71-92. https://doi.org/10.1080/19361653.2016.1256013.

Almeida, J., Johnson, R. M., Corliss, H. L., Molnar, B. E., \& Azrael, D. (2009). Emotional distress among LGBT youth: the influence of perceived discrimination based on sexual orientation. Journal of Youth and Adolescence, 38(7), 1001-1014. https:// doi.org/10.1007/s10964-009-9397-9.

American Psychiatric Association. (1987). Diagnostic and statistical manual of mental disorders. DSM-III-R (3rd ed.). Washington, DC: American Psychiatric Press.

Black, W. W., Fedewa, A. L., \& Gonzales, K. A. (2012). Effects of "safe school" programs and policies on the social climate for sexual-minority youth: A review of the literature. Journal of LGBT Youth, 9, 321-339.

Bowlby, J. (1969/1982). Attachment and Loss. Volume I. Attachment (2nd ed.). New York, NY: Basic Books. Retrieved from http:// www.abebe.org.br/wp-content/uploads/John-Bowlby-Attachment -Second-Edition-Attachment-and-Loss-Series-Vol-1-1983.pdf.

Brown, A., Rice, S., Rickwood, D., \& Parker, A. G. (2016). Systematic review of barriers and facilitators to accessing and engaging with mental health care among at-risk young people. Asia-Pacific Psychiatry, 8, 3-22. https://doi.org/10.1111/appy.12199.

Bouris, A., Guilamo-Ramos, V., Pickard, A., Shiu, C., Loosier, P. S., Dittus, P., et al. (2010). A systematic review of parental influences on the health and well-being of lesbian, gay, and bisexual youth: Time for a new public health research and practice agenda. Journal of Primary Prevention, 31, 273-309.

Bryan, A., \& Mayock, P. (2017). Supporting LGBT lives? Complicating the suicide consensus in LGBT mental health research. Sexualities, 20(1-2), 65-85. https://doi.org/10.1177/1363460716 648099.

Buote, D., Darwich, L., Hymel, S., Waterhouse, T., \& Danbrook, M. (2012). The health of LGBTQ youth: Risk and protective factors. Health Canada. Retrieved from http://arboreducational.com/wpcontent/uploads/2013/11/GLBTQ-Youth_May-2012_HC.pdf.

* Capous-Desyllas, M., \& Barron, C. (2017). Identifying and navigating social and institutional challenges of transgender children and families. Child and Adolescent Social Work Journal, 34, 527-542. https://doi.org/10.1007/s10560-017-0491-7.

* Catalpa, J. M., \& McGuire, J. K. (2018). Family boundary ambiguity among transgender youth. Family Relations, 67(1), 88-103. https ://doi.org/10.1111/fare.12304.

Chakraborty, A., McManus, S., Brugha, T. S., Bebbington, P., \& King, M. (2011). Mental health of the non-heterosexual population of 
England. The British Journal of Psychiatry, 198, 143-148. https ://doi.org/10.1192/bjp.bp.110.082271.

Clark, T. (2010). On 'being researched': Why do people engage with qualitative research? Qualitative Research, 104, 399-419. https ://doi.org/10.1177/1468794110366796.

Clark, T. C., Fleming, T., Bullen, P., Denny, S., Crengle, S., Dyson, S., et al. (2013). Youth'12 Overview: The health and wellbeing of New Zealand secondary school students in 2012. Auckland: The University of Auckland.

Collier, K., van Beusekom, G., Bos, H., \& Sandfort, T. (2013). Sexual orientation and gender identity/expression related peer victimization in adolescence: A systematic review of associated psychosocial and health outcomes. Journal of Sex Research, 50(3-4), 299-317.

Community Mental Health and 7 Day Services. (2017). Preventing suicide in England: Third progress report of the cross-government outcomes strategy to save lives. London: Ministry of Health. Retrieved from www.nationalarchives.gov.uk/doc/open-gover nment-licence/.

Crossley, S. (2015). Come out come out wherever you are: A content analysis of homeless transgender youth in social service literature. PSU McNair Scholars Online Journal, 9(1), 4.

* Davis, T. S., Saltzburg, S., \& Locke, C. R. (2009). Supporting the emotional and psychological well being of sexual minority youth: Youth ideas for action. Children and Youth Services Review, 31, 1030-1041. https://doi.org/10.1016/j.childyouth.2009.05.003.

Department of Health. (2012). Preventing suicide in England: A crossgovernment outcomes strategy to save lives. London: Ministry of Health

Dessel, A. B., \& Rodenborg, N. (2017). Social workers and LGBT policies: Attitude predictors and cultural competence course outcomes. Sexuality Research \& Social Policy, 14(1), 17-31. https ://doi.org/10.1007/s13178-016-0231-3.

* Diamond, G. M., Shilo, G., Jurgensen, E., D’Augelli, A., Samarova, V., \& White, K. (2011). How depressed and suicidal sexual minority adolescents understand the causes of their distress. Journal of Gay \& Lesbian Mental Health, 15(2), 130-151. https ://doi.org/10.1080/19359705.2010.532668.

* Difulvio, G. T. (2011). Sexual minority youth, social connection and resilience: From personal struggle to collective identity. Social Science \& Medicine Journal, 72, 1611-1617. https://doi. org/10.1016/j.socscimed.2011.02.045.

Drescher, J. (2015). Out of DSM: Depathologizing homosexuality. Behavioural Science, 5, 565-575. https://doi.org/10.3390/bs504 0565 .

Durso, L. E., \& Gates, G. J. (2012). Serving our youth: Findings from a national survey of services providers working with lesbian, gay, bisexual and transgender youth who are homeless or at risk of becoming homeless. Los Angeles, CA: The Williams Institute with True Colors Fund and The Palette Fund. Retrieved from www.TrueColorsFund.org.

Fergusson, D. M., Horwood, L. J., \& Beautrais, A. L. (1999). Is sexual orientation related to mental health problems and suicidality in young people? Archives of General Psychiatry, 56(10), 876-880. https://doi.org/10.1001/archpsyc.56.10.876.

Flores, A. R., \& Park, A. (2018). Polarized progress. Social acceptance of LGBT people in 141 countries, 1981 to 2014. The Williams Institute, UCLA School of Law. Retrieved from https://willi amsinstitute.law.ucla.edu/wp-content/uploads/Polarized-Progr ess-April-2018.pdf.

* Formby, E. (2013). Understanding and responding to homophobia and bullying: Contrasting staff and young people's views within community settings in England. Sexuality Research and Social Policy, 10, 302-316. https://doi.org/10.1007/s13178-013-0135-4.

Fuhrmann, D., Knoll, L. J., \& Blakemore, S.-J. (2015). Adolescence as a sensitive period of brain development. Trends in
Cognitive Sciences, 19(10), 556-558. https://doi.org/10.1016/j. tics.2015.07.008

Gillespie, R., Florin, D., \& Gillam, S. (2002). Changing relationships: Findings from the patient involvement project. London: King's Fund. Retrieved from https://www.kingsfund.org.uk/sites/defau 1t/files/field/field_publication_file/changing-relationships-findi ngs-patient-involvement-project-rosemary-gillespie-dominiqueflorin-steve-gillam-kings-fund-1-October-2002.pdf.

GLSEN CiPHR \& CCRC. (2013). Out online. The experiences of lesbian, gay, bisexual and transgender youth on the Internet. New York, NY: GLSEN. Retrieved https://www.glsen.org/sites/defau 1t/files/Out\%20Online\%20FINAL.pdf.

Government Equalities Office. (2018). LGBT action plan. Improving the lives of lesbian, gay and transgender people. London: Government Equalities Office. Retrieved from https://assets.publi shing.service.gov.uk/government/uploads/system/uploads/attac hment_data/file/721367/GEO-LGBT-Action-Plan.pdf.

* Grafsky, E. L., Hickey, K., Nguyen, H. N., \& Wall, J. D. (2018). Youth disclosure of sexual orientation to siblings and extended family. Family Relations, 67(1), 147-160. https://doi. org/10.1111/fare.12299.

* Grossman, A. H., Haney, A. P., Edwards, P., Alessi, E. J., Ardon, M., \& Jarrett Howell, T. (2009). Lesbian, gay, bisexual and transgender youth talk about experiencing and coping with school violence: A qualitative study. Journal of LGBT Youth, 6(1), 24-46. https://doi.org/10.1080/19361650802379748.

Hadfield, M., \& Haw, K. (2001). 'Voice', young people and action research. Educational Action Research, 9(3), 485-502. https:// doi.org/10.1080/09650790100200165.

Hafeez, H., Zeshan, M., Tahir, M. A., Jahan, N., \& Naveed, S. (2017). Health care disparities among lesbian, gay, bisexual, and transgender youth: A literature review. Cureus, 9(4), e1184. https ://doi.org/10.7759/cureus.1184

* Harper, G. W., Brodsky, A., \& Bruce, D. (2012). What's good about being gay? Perspectives from youth. Journal of LGBT Youth, 9(1), 22-41. https://doi.org/10.1080/19361653.2012.628230.

* Higa, D., Hoppe, M. J., Lindhorst, T., Mincer, S., Beadnell, B., Morrison, D. M., et al. (2014). Negative and positive factors associated with the well-being of lesbian, gay, bisexual, transgender, queer, and questioning (LGBTQ) youth. Youth and Society, 46(5), 663-687. https://doi.org/10.1177/0044118X12449630.

Hillier, L., Mitchell, K. J., \& Ybarra, M. L. (2012). The internet as a safety net: Findings from a series of online focus groups with LGB and non-LGB young -people in the United States. Journal of LGBT Youth, 9(3), 225-246. https://doi.org/10.1080/19361 653.2012.684642.

Hudson-Sharp, N., \& Metcalf, H. (2016). Inequality among lesbian, gay, bisexual and transgender groups in the UK: a review of evidence. Retrieved from https://assets.publishing.service.gov.uk/ government/uploads/system/uploads/attachment_data/file/53968 2/160719_REPORT_LGBT_evidence_review_NIESR_FINAL PDF.pdf.

Human Rights Campaign. (2012). Growing up LGBT in America. HRC youth survey Report key findings. Washington, DC: Human Rights Campaign. Retrieved from https://assets2.hrc.org/files/ assets/resources/Growing-Up-LGBT-in-America_Report.pdf.

InsideOUT. (2018). InsideOUT. Kōaro - Tatū ki roto, tatū ki waho. Retrieved from http://insideout.org.nz/.

* Jones, T., \& Hillier, L. (2013). Comparing trans-spectrum and same-sex-attracted youth in Australia: Increased risks, increased activisms. Journal of LGBT Youth, 10(4), 287-307. https://doi. org/10.1080/19361653.2013.825197.

Kidd, S. A., Gaetz, S., \& O'Grady, B. (2017). The 2015 national Canadian homeless youth survey: Mental health and addiction findings. Canadian Journal of Psychiatry. Revue Canadienne 
de Psychiatrie, 62(7), 493-500. https://doi.org/10.1177/07067 43717702076.

King, M., Semlyen, J., Tai, S. S., Killaspy, H., Osborn, D., Popelyuk, D., et al. (2008). A systematic review of mental disorder, suicide, and deliberate self harm in lesbian, gay and bisexual people. BMC Psychiatry, 8, 70. https://doi.org/10.1186/1471-244X-8-70.

Kosciw, J., Greytak, E., Palmer, N., \& Boesen, M. (2014). The 2013 national school climate survey. The experiences of lesbian, gay, bisexual and transgender youth in our nation's schools. New York: GLSEN. Retrieved from www.glsen.org/research.

Kull, R. M., Kosciw, J. G., \& Greytak, E. A. (2017). Preparing school counselors to support LGBT youth: The roles of graduate education and professional development. Professional School Counseling, 20(1a), 13-20. https://doi. org/10.5330/1096-2409-20.1a.13.

Lerner, J. E., \& Robles, G. (2017). Perceived barriers and facilitators to health care utilization in the United States for transgender people: A review of recent literature. Journal of Health Care for the Poor and Underserved, 28(1), 127-152. https://doi. org/10.1353/hpu.2017.0014.

LGBT Youth Scotland (2018). LGBT charter. LGBT Youth Scotland. Retrieved from https://www.lgbtyouth.org.uk/lgbt-chart er/lgbt-charter/.

Liu, R. T., \& Mustanski, B. (2012). Suicidal ideation and self-harm in lesbian, gay, bisexual, and transgender youth. American Journal of Preventive Medicine, 42(3), 221-228. https://doi. org/10.1016/j.amepre.2011.10.023.

* Lucassen, M., Clark, T., Moselen, E., Robinson, E., \& The Adolescent Health Research Group. (2014). Youth'12 the health and wellbeing of secondary school students in New Zealand: Results for young people attracted to the same sex or both sexes. Auckland, New Zealand: The University of Auckland. Retrieved from www.youthresearch.auckland.ac.nz.

* Lucassen, M. F., \& Burford, J. (2015). Educating for diversity: an evaluation of a sexuality diversity workshop to address secondary school bullying. Australasian Psychiatry, 23(5), 544-549. https://doi.org/10.1177/1039856215592324.

Lucassen, M. F. G., Hatcher, S., Fleming, T. M., Stasiak, K., Shepherd, M. J., Merry, S., et al. (2015). A qualitative study of sexual minority young people's experiences of computerised therapy for depression. Australasian Psychiatry, 23(3), 268273. https://doi.org/10.1177/1039856215579542.

Lucassen, M. F. G., Stasiak, K., Samra, R., Frampton, C. M. A., \& Merry, S. N. (2017). Sexual minority youth and depressive symptoms or depressive disorder: A systematic review and meta-analysis of population-based studies. Australian and New Zealand Journal of Psychiatry, 51, 774-787.

Mallory, C., Brown, T. N. T., Russell, S., \& Sears, B. (2017). The impact of stigma and discrimination against LGBT people in Texas. Los Angeles, LA: The Williams Institute, UCLA School of Law. Retrieved from http://williamsinstitute.law.ucla.edu/ wp-content/uploads/Texas-Impact-of-Stigma-and-Discrimina tion-Report-April-2017.pdf.

Marx, R. A., \& Kettrey, H. H. (2016). Gay-straight alliances are associated with lower levels of school-based victimization of LGBTQ + youth: A systematic review and meta-analysis. Journal of Youth and Adolescence, 45(7), 1269-1282. https://doi. org/10.1007/s10964-016-0501-7.

Matthews, P., Poyner, C., \& Kjellgren, R. (2018). Lesbian, gay, bisexual, transgender and queer experiences of homelessness and identity: insecurity and home(o)normativity. International Journal of Housing Policy. https://doi.org/10.1080/19491 247.2018.1519341.

Mayer, K. H., Bradford, J. B., Makadon, H. J., Stall, R., Goldhammer, H., \& Landers, S. (2008). Sexual and gender minority health: What we know and what needs to be done. American Journal of Public Health, 98(6), 989-995. https://doi.org/10.2105/ AJPH.2007.127811.

* McDermott, E. (2015). Asking for help online: Lesbian, gay, bisexual and trans youth, self-harm and articulating the "failed" self. Health, 19(6), 561-577. https://doi.org/10.1177/1363459314 557967.

* McDermott, E., Hughes, E., \& Rawlings, V. (2017). The social determinants of lesbian, gay, bisexual and transgender youth suicidality in England: a mixed methods study. Journal of Public Health, 40(3), e244-e251.

* McDermott, E., Roen, K., \& Piela, A. (2013). Hard-to-reach youth online: methodological advances in self-harm research. Sexuality Research and Social Policy, 10, 125-134. https://doi. org/10.1007/s13178-012-0108-z.

* McDermott, E., Roen, K., \& Piela, A. (2015). Explaining selfharm: Youth cybertalk and marginalized sexualities and genders. Youth \& Society, 47(6), 873-889. https://doi. org/10.1177/0044118X13489142.

* McDermott, E., Roen, K., \& Scourfield, J. (2008). Avoiding shame: Young LGBT people, homophobia and self-destructive behaviours. Culture, Health \& Sexuality, 10(8), 815-829. https://doi. org/10.1080/13691050802380974.

McDonald, K. (2018). Issues in mental health nursing social support and mental health in LGBTQ adolescents: A review of the literature social support and mental health in LGBTQ adolescents: A review of the literature. Issues in Mental Health Nursing, 39(1), 16-29. https://doi.org/10.1080/01612840.2017.1398283.

* McGlashan, H., \& Fitzpatrick, K. (2017). LGBTQ youth activism and school: Challenging sexuality and gender norms. Health Education, 117(5), 485-497. https://doi.org/10.1108/ HE-10-2016-0053.

* McGuire, J. K., Anderson, C. R., Toomey, R. B., \& Russell, S. T. (2010). School climate for transgender youth: A mixed method investigation of student experiences and school responses. Journal of Youth and Adolescence, 39, 1175-1188. https://doi. org/10.1007/s10964-010-9540-7.

McLaughlin, H. (2015). Involving children and young people in policy, practice and research: An introduction. In H. McLaughlin (Ed.), Involving children and young people in policy, practice and research (pp. 5-13). London: NCB.

McLeod, J. (2010). Process research: Using qualitative methods to explore therapeutic practice around issues of fear and sadness. In D. Langdridge, M. Barker, \& A. Vossler (Eds.), Understanding counselling and psychotherapy (pp. 307-326). Milton Keynes: Open University Press.

Meade, M. O., \& Richardson, W. S. (1997). Selecting and appraising studies for a systematic review. Annals of Internal Medicine, 127(7), 531-537. https://doi.org/10.7326/0003-4819-127-7199710010-00005.

Mental Health Foundation. (2016). Mental health in Scotland: fundamental facts. Retrieved from www.mentalhealth.org.uk.

Meyer, I. H. (2003). Prejudice, social stress, and mental health in lesbian, gay, and bisexual populations: Conceptual issues and research evidence. Psychological Bulletin, 129(5), 674-697. https://doi.org/10.1037/0033-2909.129.5.674.

Ministry of Education. (2015). Sexuality education: A guide for principals, boards of trustees, and teachers. Wellington: Ministry of Education.

Ministry of Youth Affairs. (2002). Youth development strategy Aotearoa. Action for child and youth development. Wellington New Zealand: Ministry of Youth Affairs. Retrieved from http:// www.youthpolicy.org/national/New_Zealand_2002_Youth _Development_Strategy.pdf.

Ministry of Youth Development. (2015). Supporting LGBTI young people in New Zealand. Wellington, New Zealand: Ministry of Youth Development. Retrieved from http://www.msd.govt.nz/ 
documents/about-msd-and-our-work/newsroom/lgbti-releaseministry-of-youth-development.pdf.

Mockler, N., \& Groundwater-Smith, S. (2015). Engaging with student voice in research, education and community. Beyond Legitimisation and Guardianship. Ourimbah and Sydney: Springer.

Mohr, J. J., \& Fassinger, R. E. (2003). Self-acceptance and self-disclosure of sexual orientation in lesbian, gay, and bisexual adults: An attachment perspective. Journal of Counseling Psychology, 50(4), 482-495. https://doi.org/10.1037/0022-0167.50.4.482.

Mulé, N. J., Ross, L. E., Deeprose, B., Jackson, B. E., Daley, A., Travers, A., et al. (2009). Promoting LGBT health and wellbeing through inclusive policy development. International Journal for Equity in Health, 8, 18. https://doi.org/10.1186/1475-9276-8-18.

* Nadal, K. L., Issa, M.-A., Leon, J., Meterko, V., Wideman, M., \& Wong, Y. (2011). Sexual orientation microaggressions: "Death by a thousand cuts" for lesbian, gay, and bisexual youth. Journal of LGBT Youth, 8, 234-259. https://doi.org/10.1080/19361 653.2011.584204.

NICE. (2012a). Appendix H. Examples of evidence tables. Retrieved from https://www.nice.org.uk/process/pmg10/resources/appen dix-h-examples-of-evidence-tables-pdf-4476228445.

NICE. (2012b). Appendix H Quality appraisal checklist - qualitative studies. Retrieved from https://www.nice.org.uk/process/pmg4/ chapter/appendix-h-quality-appraisal-checklist-qualitative-studi es.

Oakley, S., \& Bletsas, A. (2018). The experiences of being a young LGBTIQ and homeless in Australia: Re-thinking policy and practice. Journal of Sociology, 54(3), 381-395. https://doi. org/10.1177/1440783317726373.

Office for National Statistics. (2016). Sexual identity, UK: 2016. Retrieved from http://doi.wiley.com/10.1002/9781119085621. wbefs073.

Oxford Dictionaries. (2018). Definition of marginalization. Retrieved https://en.oxforddictionaries.com/definition/marginalization.

* Pallotta-Chiarolli, M., \& Martin, E. (2009). "Which sexuality? Which service?" Bisexual young people's experiences with youth, queer and mental health services in Australia. Journal of LGBT Youth, 6(2-3), 199-222. https://doi.org/10.1080/19361650902927719.

Perez-Brumer, A., Day, J. K., Russell, S. T., \& Hatzenbuehler, M. L. (2017). Prevalence and correlates of suicidal ideation among transgender youth in California: Findings from a representative, population-based sample of high school students. Journal of the American Academy of Child \& Adolescent Psychiatry, 56(9), 739-746. https://doi.org/10.1016/j.jaac.2017.06.010.

* Peter, T., Taylor, C., \& Campbell, C. (2016). "You can't break... when you're already broken": The importance of school climate to suicidality among LGBTQ youth. Journal of Gay \& Lesbian Mental Health, 20(3), 195-213.

Peterson, C. M., Matthews, A., Copps-Smith, E., \& Conard, L. A. (2017). Suicidality, self-harm, and body dissatisfaction in transgender adolescents and emerging adults with gender dysphoria. Suicide and Life-Threatening Behavior, 47(4), 475-482. https://doi.org/10.1111/sltb.12289.

Pompili, M., Lester, D., Forte, A., Seretti, M. E., Erbuto, D., Lamis, D. A., et al. (2014). Bisexuality and suicide: A systematic review of the current literature. Journal of Sexual Medicine, 11, 1903-1913.

* Porta, C. M., Gower, A. L., Mehus, C. J., Yu, X., Saewyc, E. M., \& Eisenberg, M. E. (2017). "Kicked out": LGBTQ youths' bathroom experiences and preferences. Journal of Adolescence, 56, 107-112. https://doi.org/10.1016/j.adolescence.2017.02.005.

Poteat, V. P., Calzo, J. P., \& Yoshikawa, H. (2016). Promoting youth agency through dimensions of gay-straight alliance involvement and conditions that maximize associations. Journal of Youth and
Adolescence, 45(7), 1438-1451. https://doi.org/10.1007/s1096 4-016-0421-6.

Poteat, V. P., Calzo, J. P., \& Yoshikawa, H. (2018). Gay-straight alliance involvement and youths' participation in civic engagement, advocacy, and awareness-raising. Journal of Applied Developmental Psychology, 56, 13-20. https://doi.org/10.1016/j.appde v.2018.01.001.

Prock, K. A., \& Kennedy, A. C. (2017). Federally-funded transitional living programs and services for LGBTQ-identified homeless youth: A profile in unmet need. Children and Youth Services Review, 83, 17-24. https://doi.org/10.1016/j.childyouth .2017.10.023.

RainbowYOUTH. (2018). RainbowYOUTH IAotearoa. Retrieved from https://www.ry.org.nz/.

* Roffee, J. A., \& Waling, A. (2016). Rethinking microaggressions and anti-social behaviour against LGBTIQ + youth. Safer Communities, 15(4), 190-201.

Russell, S. T., \& Fish, J. N. (2016). Mental health in lesbian, gay, bisexual, and transgender (LGBT) Youth. Annual Review of Clinical Psychology, 12, 465-487. https://doi.org/10.1146/annurev-clinp sy-021815-093153.

* Russell, S. T., Muraco, A., Subramaniam, A., \& Laub, C. (2009). Youth empowerment and high school gay-straight alliances. Journal of Youth and Adolescence, 38(7), 891-903. https://doi. org/10.1007/s10964-008-9382-8.

Ryan, C., Russell, S. T., Huebner, D., Diaz, R., \& Sanchez, J. (2010). Family acceptance in adolescence and the health of LGBT young adults. Journal of Child and Adolescent Psychiatric Nursing, 23(4), 205-213. https://doi.org/10.1111/j.1744-6171.2010.00246.x.

* Saltzburg, S., \& Davis, T. (2010). Co-authoring gender-queer youth identities: Discursive tellings and retellings. Journal of Ethnic \& Cultural Diversity in Social Work, 19(2), 87-108. https://doi. org/10.1080/15313200903124028.

* Scourfield, J., Roen, K., \& McDermott, L. (2008). Lesbian, gay, bisexual and transgender young people's experiences of distress: Resilience, ambivalence and self-destructive behaviour. Health and Social Care in the Community, 16(3), 329-336. https://doi. org/10.1111/j.1365-2524.2008.00769.x.

* Sherriff, N. S., Hamilton, W. E., Wigmore, S., \& Giambrone, B. L. B. (2011). "What do you say to them?" Investigating and supporting the needs of lesbian, gay, bisexual, trans, and questioning (LGBTQ) young people. Journal of Community Psychology, 39(8), 939-955. https://doi.org/10.1002/jcop.20479.

Silenzio, V. M. B., Pena, J. B., Duberstein, P. R., Cerel, J., \& Knox, K. L. (2007). Sexual orientation and risk factors for suicidal ideation and suicide attempts among adolescents and young adults. American Journal of Public Health, 97(11), 2017-2019. https:// doi.org/10.2105/AJPH.2006.095943.

Singh, A. A., Hays, D. G., \& Watson, L. S. (2011). Strength in the face of adversity: Resilience strategies of transgender individuals. Journal of Counseling and Development, 89, 20-27.

Sitkin, N. A., \& Murota, D. (2017). Moving beyond the basics of the binary: Addressing mental health needs and suicidality among transgender youth. Journal of the American Academy of Child \& Adolescent Psychiatry, 56(9), 725-726. https://doi.org/10.1016/j. jaac.2017.07.005.

* Snapp, S., Burdge, H., Licona, A. C., Moody, R. L., \& Russell, S. T. (2015). Students' perspectives on LGBTQ-inclusive curriculum. Equity \& Excellence in Education, 48(2), 249-265.

* Steinke, J., Root-Bowman, M., Estabrook, S., Levine, D. S. W., \& Kantor, L. M. (2017). Meeting the needs of sexual and gender minority youth: Formative research on potential digital health interventions. Journal of Adolescent Health, 60, 541-548. https ://doi.org/10.1016/j.jadohealth.2016.11.023. 
Stone, D. M., Luo, F., Lippy, C., \& McIntosh, W. L. (2015). The role of social connectedness and sexual orientation in the prevention of youth suicide ideation and attempts among sexually active adolescents. Suicide and Life-Threatening Behavior, 45(4), 415-430. https://doi.org/10.1111/sltb.12139.

Stonewall Scotland. (2018). Engaging LGBT people in your work. Retrieved from https://www.equality-network.org/wp-content/ uploads/2013/02/Community-Connections-1.-Engaging-LGBTPeople.pdf.

Sutton, J., \& Austin, Z. (2015). Qualitative research: Data collection, analysis, and management. The Canadian Journal of Hospital Pharmacy, 68(3), 226-231.

Swanson, K., \& Gettinger, M. (2016). Teachers' knowledge, attitudes, and supportive behaviors toward LGBT students: Relationship to Gay-Straight Alliances, antibullying policy, and teacher training. ERIC, 13(4), 326-351. https://doi.org/10.1080/19361 653.2016.1185765org/10.1080/19361653.2016.1185765.

Thomas, J., \& Harden, A. (2008). Methods for the thematic synthesis of qualitative research in systematic reviews. BMC Medical Research Methodology, 8, 45. https://doi. org/10.1186/1471-2288-8-45.

Tishelman, A. C., Kaufman, R., Edwards-Leeper, L., Mandel, F. H., Shumer, D. E., \& Spack, N. P. (2015). Serving transgender youth: Challenges, dilemmas and clinical examples. Professional Psychology, Research and Practice, 46(1), 37-45.

Trans Student Educational Resources (2018). LGBTQ+ definitions. Retrieved from http://www.transstudent.org/definitions/.

U.S. Department of Health and Human Services. (2017). LGBTQ youth. Retrieved from https://www.stopbullying.gov/at-risk/ groups/lgbt/index.html.

United Nations Human Rights Office. (2011). Tackling discrimination on grounds of sexual orientation and gender identity. Retrieved from https://www.ohchr.org/Documents/Issues/Discrimination/ LGBT_discrimination_A4.pdf.
UN Committee on the Rights of the Child. (2003). General comment No. 4 (2003): Adolescent Health and Development in the Context of the Convention on the Rights of the Child. Retrieved from https ://www.refworld.org/docid/4538834f0.html.

UNICEF. (1990). The United Nations convention on the rights of the child. Retrieved from https://downloads.unicef.org.uk/wp-conte nt/uploads/2010/05/UNCRC_united_nations_convention_on the_rights_of_the_child.pdf?_ga=2.90812051.804002699.15317 16962-59161298.1531716962.

* Waling, A., \& Roffee, J. A. (2018). Supporting LGBTIQ+students in higher education in Australia: Diversity, inclusion and visibility. Health Education Journal. https://doi.org/10.1177/00178 96918762233.

Wilson, B. D. M., Cooper, K., Kastanis, A., \& Nezhad, S. (2014). Sexual and gender minority youth in foster care: Assessing disproportionality and disparities in los angeles. Los Angeles, CA: The William Institute. Retrieved from: http://williamsinstitute.law. ucla.edu/wp-content/uploads/LAFYS_report_final-aug-2014.pdf.

* Wolff, J. R., Allen, K. D., Himes, H. L., Fish, A. E., \& Losardo, J. R. (2014). A Retrospective examination of completed sexual and gender minority youth suicides in the United States: What can be learned from written online media? Journal of Gay \& Lesbian Mental Health, 18(1), 3-30. https://doi.org/10.1080/19359 705.2013.827607.

World Health Organisation. (1990). ICD-10: International statistical classification of diseases and related health problems: Tenth Revision. Retrieved from https://www.who.int/classifications/ icd/en/.

Publisher's Note Springer Nature remains neutral with regard to jurisdictional claims in published maps and institutional affiliations. 